\title{
La COlONIZACión AGRARIA DEL SIgLO XVIII en ANDALUCía: EL PROYECTO ILUSTRADO PARA EL ESPACIO DE DOÑANA
}

\author{
Domingo Muñoz Bort \\ UNIVERSIDAD DE HUELVA
}

Fecha de recepción: 15/11/209

Fecha de aceptación: 03/03/2010

\section{RESUMEN}

A nivel historiográfico, las Nuevas Poblaciones destacan como la realización práctica de la Ilustración dieciochesca, despreciándose la participación de la iniciativa privada en proyectos similares que se extendieron por todo el territorio nacional. Para lo que hoy es la Provincia de Huelva disponemos de un solo proyecto y de una realización práctica: Guzmanópolis y la Nueva Población del Rocío, desarrollados en la comarca de Dońana. Centramos nuestra atención en el primero por su cronología y por la mediación de Pablo de Olavide. El proyecto sufrió las contradicciones políticas de los propios reformistas y fracasó en la misma medida que los ideales de muchos de aquellos prohombres ilustres.

\section{Palabras Clave}

Siglo XVIII. Ilustración. Nuevas Poblaciones. Dońana. Pablo de Olavide

\section{Abstract}

From the point of view of Historiography, the New Settlements stand out as practical performances of the Spanish Enlightenment, which despised the participation of private initiatives in many other similar projects that took place within the national territory. In the province of Huelva, only one project (Guzmanópolis) and a new settlement in el Rocío took place in the area of Doñana. Our study focuses on Guzmanópolis, an interesting case because of its development and for Pablo de Olavide's role. The project proved the political contradictions of the reformers and failed as did many ideals of the enlightened men of the period.

\section{KEY WORDS}

18th century, Enlightenment, new settlements, Doñana, Pablo de Olavide

\section{El marco ilustrado de las nuevas poblaciones en Andalucía.}

La Ilustración Española fue en gran medida una revolución de ideas reformistas; aunque más acertadamente podía definirse como una revolución legislativa de proyectos más que de realizaciones concretas desarrolladas por los gabinetes del despotismo monárquico para la modernización general del país: fomento económico, mejora de la organización social, bienestar general y felicidad de los vasallos. Basta con examinar el corpus legislativo de los ańos de Carlos III y Carlos IV; cientos de reales órdenes, cédulas e instrucciones salieron anualmente de aquellos ministerios intentando reformar la sociedad espańola y las propias instituciones que las gobernaban. Planteamientos principalmente crematísticos, algunos importados, que irradiaron y 
tuvieron eco en varios segmentos de la sociedad espańola que actuaron al unísono y con rapidez. Todos los sectores productivos de la nación fueron examinados, descubriéndose decadencia y anquilosamiento en cualquiera de ellos. En estos años se recordaban y reivindicaban a muchos pensadores espańoles de la centuria anterior y de la primera mitad del XVIII que habían denunciado y propuesto soluciones a los males patrios; actitudes que por sí mismas indicaban la antigüedad y la pervivencia del declive económico de la nación. Los ańos de la segunda mitad del siglo XVIII vieron aparecer cientos de libros, revistas y folletos de autores españoles y extranjeros aportando miles de soluciones para la regeneración del reino. Destacaba esta prolija literatura que entre los grandes males que acuciaban a la madre patria estaban la despoblación, los inmensos terrenos sin cultivar y una agricultura tradicional incapaz de abastecer a los ciudadanos y a la industria manufacturera.

La realización quizás más brillante del periodo ilustrado fueron las nuevas poblaciones de Sierra Morena y de Andalucía desparramadas por los yermos del camino real de Madrid a Sevilla; precisamente por no haberse quedado en mero proyecto legislativo como tantos otros del reinado de Carlos III.

Aquellas nuevas poblaciones del Setecientos se convirtieron en el paradigma de los historiadores que se ocupaban de las colonizaciones en España, provocando "la fortuna historiográfica de las nuevas poblaciones carolinas", como acertadamente definió el profesor Miguel Avilés, que a la altura de 1990 había producido más de ciento cincuenta referencias bibliográficas entre monografías y artículos. ${ }^{1}$ Además ha inducido, desde 1983, seis congresos monográficos, donde tuvieron cabida otros procesos colonizadores fuera de los ámbitos geográficos y cronológicos de las nuevas colonias de Ciudad Real, Jaén, Córdoba y Sevilla.

No han tenido la misma oportunidad historiográfica otros proyectos y realizaciones pobladoras de la Ilustración Española. Los grandes olvidados han sido el puñado de ciudadanos que acudieron a la llamada de los soberanos para que, a su imitación, emprendieran proyectos de nuevas poblaciones y recolonizaciones, cuyo volumen y dispersión geográfica han merecido poca atención. En Andalucía, la iniciativa privada ayudó, e intentó en otros casos, a Pablo de Olavide a extender su proyecto de reforma agraria a toda la región mediante la colonización de terrenos baldíos en las provincias de Granada, Cádiz y Huelva, alejándose incluso del mítico trayecto del camino real de Madrid a Cádiz.

A esta tierra confinada de Huelva también llegaron aquellos ilustres ecos, pero poco se podía esperar de una masa analfabeta de campesinos y pescadores. Pero a pesar de este lastre algunos de sus ciudadanos más instruidos respondieron en la producción cultural histórica y geográfica --magníficamente resumidos por el profesor Moreno Alonso-- ${ }^{2}$, otros eruditos en la mejora de los sistemas de cultivos, otros en

1 AVILÉS, M.: "Historiografía sobre las <Nuevas Poblaciones> de Carlos III". En Coloquio Internacional Carlos III y su siglo. Actas. Madrid, 1990, t. I, pp. 485-510.

2 MORENO ALONSO, M.: "Historiografía de Huelva Ilustrada", en JAVIER PÉREZ-EMBID y otros: Historia e historiadores sobre Huelva (Siglos XVI-XIX), Ayuntamiento de Huelva, Huelva, 1997, 
levantar fábricas, otros en la introducción de cultivos en zonas vírgenes, otros planearon repoblar los grandes espacios deshabitados y algunos, incluso, intentaron que las nuevas ideas de los "philósofos" se aplicaran a una política municipal instrumentalizada por la rancia oligarquía local. Los primeros prohombres ilustres onubenses ya fueron reivindicados; la gran mayoría de los otros siguen en el anonimato.

Una de las facetas de la Ilustración en Huelva, el de su movimiento intelectual, es quizás la que más atención ha despertado y la que más trabajos ha producido en los últimos años; en su mayoría realizados por un especialista en Historia de las Mentalidades, el profesor Manuel José de Lara Ródenas, quién con inquietud observaba aquel desierto historiográfico:

"Apenas hay nada estudiado sobre la Ilustración onubense. En sí, eso no supone una gran novedad, puesto que las lagunas de la Historia Moderna de Huelva son los suficientemente profundas y caudalosas como para que, en general, pueda decirse lo mismo de muchos otros ámbitos de la investigación histórica onubense. Sin embargo, el campo de la Historia de los hechos culturales -o, si preferimos una expresión más precisa para lo que vamos a abordar, el de la Historia de la cultura escrita o de las formas de la cultura intelectual - ha sido hasta el momento tan poco tratada en Huelva y aparece hoy tan disminuido respecto a otros sectores que actuar sobre esa descompensación comporta ya caracteres de urgencia" ${ }^{3}$

En los años siguientes el profesor Lara fue publicando las biografías de aquellos onubenses que formaron parte importante del contingente de la intelectualidad ilustrada de la España del XVIII; estudios que recogían también la aportación, más o menos brillante, de estos biografiados en mejorar el bienestar general de la patria y de sus súbditos. ${ }^{4}$ Hoy, cuanto se redacta este trabajo, siguen existiendo importantísimos vacíos, más preguntas que respuestas -en el decir popular-- sobre la Huelva de la Ilustración.

A tenor de lo que va expuesto y de este ambiente ilustrado que se iniciaba en Huelva, apostamos por investigar el único proyecto que de la mano de Pablo de Olavide se realizaría en tierras de Huelva. Estudio que creemos de interés para la historiografía de esta provincia y de la época de la Ilustración en general, ya que fue promovido por iniciativa particular. Además, los estudios de repoblaciones y de nuevas colonias agrícolas ajenas al impulso de la Real Hacienda en el Siglo de las Luces escasean y a los existentes se les han dedicado, en el mejor de los casos, pequeños opúsculos en reuniones científicas; las más de las ocasiones sólo unas líneas referenciales en obras de temática general sobre algunas facetas del siglo XVIII.

pp.173-202

3 LARA RÓDEMAS, M. J. de: Un heterodoxo en la Huelva de la Ilustración: Miguel Ignacio Pérez Quintero. Huelva, 1995, p. 15.

4 La Ilustración en las sacristías. El Vicario de Huelva y las respuestas a Tomás López. Huelva, 1998. Y José Isidoro Morales, un matemático en la Corte de Carlos IV. Huelva, 2001. 
El proyecto de la nueva población Guzmanópolis que deseaba realizar Fernando Pérez de Guzmán en los baldíos de la villa de Almonte no fue una idea singular ni aislada de aquellos ańos sino que formaba parte de la respuesta de muchos ciudadanos a la invitación del gobierno ilustrado de Carlos III de poner en cultivo tierras hasta ahora incultas o abandonadas por despoblaciones continuadas; respuesta ciudadana que alcanzó un alto nivel y que fue toda una "explosión reformista del siglo ilustrado", como definiese Rafael Rodríguez-Moñino. ${ }^{5}$

En Andalucía, además de las poblaciones celebérrimas, se realizaron en 1768 con dinero público los proyectos de Tablada y Tabladilla (Sevilla) y las de Armajal y Prado del Rey (Cádiz). Mientras que Pablo de Olavide apoya al conde del Portillo su intento de crear nuevas poblaciones en los baldíos realengos de Espiel, Hornachuelos y Montoro y al marqués de Santa Cruz para una nueva colonia en su dehesa de La Cañada del Águila próxima a las colonias; ambas en 1773. Igualmente apoya los proyectos de Rafael González en Monedero (Espiel, 1774) y de Domingo López de Carvajal en Algar (Jerez, 1775). En estos casos, Pablo de Olavide incumple la normativa de las Instrucciones de $1770 .{ }^{6}$

Promovidos sin duda alguna por particulares, disponemos de información veraz de trece proyectos de los cuales ocho se llevaron a cabo:

1. Santa María de Guadalupe de Algar, término de Jerez de la Frontera (Cádiz), fundación de Domingo Francisco López de Carvajal y Freire. 1767.

2. Francisco Bruna y Ahumada, decano de la Real Audiencia de Sevilla, de levantar dos pueblos en su finca La Serrezuela, hoy conocidos por Lagar Nuevo y El Palacio en Dos Hermanas (Sevilla). 1768.

3. Lantiscal del Membrillo en término de Lora del Río (Sevilla). 1768.

4. Miguel de Gijón y León en la costa de Granada. 1768.

5. La nueva población de Vista Hermosa de la Serrezuela, iniciativa del marqués de La Serrezuela sobre una dehesa boyal de Dos Hermanas (Sevilla). 1768.

6. La Nueva Población del Rocío, en la villa de Almonte (Huelva) iniciada por el duque de Alba a finales de 1788, objeto de nuestro trabajo de investigación.

7. Francisco Sánchez Gadeo y su nueva población de Zafarraya (Granada). Fines del XVIII.

8. José Torre y García, vecino de Canillar, la nueva población de Canillas del Aceituno, hoy en término de la provincia de Málaga. S/F.

Penosos trámites, meras solicitudes y titubeos fueron los proyectos particulares de:

1. Fernando Pérez de Guzmán con el proyecto de la nueva población de Guzmanópolis en baldíos de la villa de Almonte (Huelva). 1768.

2. Mateo del Castillo en la serranía de Constantina (Sevilla). 1768.

5 RODRÍGUEZ-MONIINO SORIANO, R.: "Las nuevas poblaciones (y repoblación de sitios y lugares) durante el siglo XVIII e inicios del XIX en los fondos documentales del Archivo Histórico Nacional". Boletín de la Real Academia de Córdoba, no 135, julio-diciembre, 1998, p. 271.

6 DEFOURNEAUX, M.: Pablo de Olavide el afrancesado. Sevilla, 1990, p. 456. 
3. José Rafael González con la nueva población de El Carmen en unos despoblados de Espiel (Córdoba). 1769.

4. El proyecto de Juan Manuel de Echaniz y seis socios con varios poblados en baldíos de Hornachuelos y Espiel (Córdoba) para agregarlos a las Nuevas Poblaciones de Andalucía. 1776.

5. El Monasterio de Valparaíso de la Orden de San Jerónimo de Córdoba para una nueva población junto a la granja llamada de "El Catalán” (Córdoba capital). S/F.

6. Manuel Martínez de Tejada y consortes, vecinos y del comercio de Zafra, solicitaron tierras al sitio Era de Santa María, término de Hornachuelos (Córdoba) para hacer una nueva población. S/F.

De todos estos proyectos y realizaciones andaluzas tuvo conocimiento puntual Pablo de Olavide y en algunos de ellos su intervención directa dirimió conflictos, aceleró los trámites y logró su éxito mientras desempeñó su cargo de Superintendente de las Nuevas Poblaciones de Sierra Morena y Andalucía entre los años de 1767 a 1776.

\section{El espacio silvopastoril de Doñana y su ENTORNo.}

Este espacio, como la mayoría del territorio almonteño, se inscribe en el área más externa de la depresión del Guadalquivir y la mayoría de sus componentes geológicos son cuaternarios y recientes, donde domina la planitud formada a finales del terciario con su manto detrítico del Pleistoceno. Pero, siguiendo al profesor Ojeda, ${ }^{7}$ esta aparente unidad geológica encierra muchos contrastes morfodinámicos y biogeográficos y su horizontalidad está compuesta de una amplia muestra de geofacies "cada una de ellas con su personalidad edáfica y ecodinámica”. El terreno que eligieron los proyectistas ilustrados, justo al borde de la marisma, son suelos arenosos al que podemos clasificar de inmaduro, cuyo manto de arena superficial cubren en algunos lugares un substrato de arcillas compactas y evolucionadas, conocidas como "vegas relictas", producto de la dinámica del drenaje aéreo-subaéreo, de la salinidad y de las interinfluencias marino-continentales. Pero, existen en el término unas áreas microclimáticas que se diferencian de esta caracterización general mesoclimática del término de Almonte y que inciden en los aprovechamientos agrícolas y en las condiciones de habitabilidad. Una sería la zona costera y litoral con fuertes vientos que provocan aumento de la temperatura y una gran sequedad; otra las zonas de matorral no arbolado en zonas arenosas con menos altitud que el resto del término municipal que los lugareños las llaman "friales" ya que en algunos inviernos se producen heladas nocturnas, concretamente en unos cinco kilómetros en torno a la aldea del Rocío, microclima propiciado por la proximidad de la marisma, la capacidad de cambio térmico de las arenas y el freno que produce el alto cordón litoral a los vientos oceánicos. Espacio, pues, destinado desde antiguo principalmente a la caza y al pastoreo y, en las zonas más próxi-

7 OJEDA RIVERA, J. F.: Organización del territorio en Doñana y su entorno próximo (Almonte). Siglos XVIII-XX. Madrid (M.A.P.A, I.C.O.N.A.), 1987, pp. 17-24. 
mas a la villa de Almonte, a la producción de cereales mediante la práctica de rozas. Estas circunstancias geográficas que ocupan la mayor parte del término de Almonte determinaron que su principal producción fuera la ganadera hasta mediados del siglo XVIII, décadas que vieron a la agricultura capitalista igualar a la renta ganadera. Aún así, Almonte, en estas fechas del Catastro de Ensenada, disponía de una cabaña ganadera que ocupa los primeros lugares de la actual provincia de Huelva. ${ }^{8}$

Los pastizales de las marismas almonteńas fueron compartidas por las hermandades surgidas por privilegio real en el siglo XIII: en 1269 Alfonso X crea las de Niebla, Huelva, Gibraleón y Ayamonte y las de Sevilla, Carmona, Jerez, Arcos de las Frontera, Medina Sidonia, Alcalá de los Gazules, Vejer, Huelva y Gibraleón. No sabemos con exactitud si las Islas Menor y Mayor, Veras, Aguijones y Marismas del Guadalquivir que Alfonso X adscribiera en el año 1253 a la ciudad de Sevilla, afectara a las marismas almonteńas en cuanto aprovechamientos de pastos, aunque creemos tal posibilidad por los acuerdos alcanzados para que los vecinos de Niebla pastasen en dicha zona desde finales del siglo XIV. ${ }^{9}$ Con el tiempo, consolidada la repoblación y alejada la frontera, estas macro hermandades se fueron debilitando y reduciendo su ámbito comunal a los términos vecinos de villas y aldeas.

El término occidental de la Niebla castellana llegaba hasta el Guadalquivir, es decir, incluía las dehesas de Las Rocinas, La Figuera y El Carrizal; la posterior presión del lugar de Almonte y de los Guzmanes de Sanlúcar segregaron de Niebla aquella inmensa porción de terrenos; los primeros ampliaron su territorio desde el Charco de los Ballesteros, Río del Oro y Las Rocinas hasta la Canaliega, los segundos se anexionaron aquellas dos dehesas que conformaron el Bosque de Las Rocinas, luego el Coto de Dońana. ${ }^{10}$ Los problemas surgidos entre Niebla y sus aldeas para pastar en término de Almonte comienzan desde que se creara ésta como aldea separada de Niebla en torno a 1335 y pasara a manos de su primer señor jurisdiccional Alvar Pérez de Guzmán; ${ }^{11}$ pleitos y deslindes que llenan de documentos los archivos de Niebla, Almonte, Chancillería de Granada y Ducal de Medina Sidonia durante los siglos XIV al XVIII.

Otra hermandad de pastos en esta área de Doñana fue la establecida entre Almonte e Hinojos; no sabemos con exactitud cuando surge, aunque dentro del siglo XIV; sólo disponemos de la existencia de sentencias favorables de la Real Chancillería de Granada al mantenimiento de dicha hermandad fechadas en 1589 y 1598 , que se re-

8 NÚNEEZ ROLDÁN, F.: En los confines del Reino. Huelva y su tierra en el siglo XVIII. Sevilla, 1987, pp. $472-474$.

9 CARMONA RUÍZ, M. A.: La ganadería en el Reino de Sevilla durante la Edad Media. Sevilla, 1998, pp. 133, 237 y 251

10 ÁlVAREZ DE TOLEDO, M. L.: "Almonte. De lugar de Niebla a señorío”, en Revista de Feria de Almonte 2005, pp. 19-20.

11 LADERO QUESADA, M. A.: "Los señoríos medievales onubenses. Período de formación”, en CARRIAZO RUBIO, J. L. y MIURA ANDRADES, J. M. (Eds.): Huelva en la Edad Media 20 años después. Huelva, 1998, p. 215 
cogieron en el acta capitular del cabildo de Almonte de 28 de agosto de $1773,{ }^{12}$ datos que no hablan de su perdurabilidad a lo largo del Antiguo Régimen.

\section{El círculo de Olavide: Fernando Pérez de Guzmán.}

La estancia de Olavide en Sevilla ${ }^{13}$ no se limitó exclusivamente a desarrollar y cumplir con todo celo su extenso y amplio cometido gubernamental, sino que trató de impulsar y poner en práctica muchos de los ideales ilustrados que compartía con sus amigos y estadistas Campomanes, Floridablanca, Múzquiz y Aranda, que desde la Corte le prestaban el apoyo necesario. Las tertulias en su residencia del Alcázar no sólo sirvieron para ponerse al día de los asuntos cotidianos y de los problemas que acuciaban a la ciudad de Sevilla y al campo andaluz, sino también para buscar adeptos a su amplia política reformadora entre todos los sectores y estamentos sociales de la capital andaluza. Fernando Pérez de Guzmán, nuestro proyectista ilustrado, a la sazón Teniente Coronel del Regimiento de Milicias Provincial de Sevilla, despacharía pronto con Olavide, su jefe superior militar. Además dentro del denominado "equipo ilustrado sevillano" 14 de Olavide, la Junta de Propios y Arbitrios de la ciudad, se hallaba un tal Pedro José Pérez de Guzmán el Bueno, con toda posibilidad hermano de nuestro proyectista.

Con su resuelta e ilimitada capacidad de trabajo quiso poner orden inmediatamente en la anquilosada, irregular e incluso corrupta administración municipal sevillana, hacer cumplir con las primeras resoluciones reales sobre arbitrios y consumos, reordenar y adecentar urbanísticamente la ciudad, reabrir el teatro de comedias, reformar los planes de estudios universitarios, crear un hospicio y reformatorio para pobres, etc.

Pero su ímpetu reformador sobrepasó con creces sus posicionamientos teóricos y cometidos gubernamentales. Apenas esbozados los preliminares de las nuevas poblaciones de Sierra Morena, solicitaba al Ministerio de Hacienda la creación de entidades similares en los despoblados de las actuales provincias de Córdoba y Sevilla, proyecto que le fue aprobado en septiembre de 1768, y cuyo centro de operaciones se estable-

12 Archivo Municipal de Almonte (AMA), leg. 11.

13 Unos días antes de publicarse el Fuero de Nuevas Poblaciones, el gobierno efectuaba el nombramiento de Pablo de Olavide y Jaúregui como Superintendente de las Nuevas Poblaciones y de las Rentas Provinciales del Reino de Sevilla, el de Asistente de la ciudad de Sevilla e Intendente del Ejército de los cuatro Reinos de Andalucía. Vid.: CAPEL MARGARITO, M.: "Pablo de Olavide, artífice de la Colonización de Sierra Morena y Andalucía y fundador de su capitalidad, Real Carolina (Proyecto de recuperación de su verdadera imagen)", en AVILÉS FERNÁNDEZ, M. y SENA MEDINA, G. (Eds.): "Las Nuevas Poblaciones" de Carlos III en Sierra Morena y Andalucía., Córdoba, 1985, p. 352. Antes de pasar a Sevilla, visita Bailén, reconoce los terrenos y ordena la preparación de la infraestructura necesaria para acoger los primeros colonos que se esperaban en septiembre. Vid.: SUÁREZ GALLEGO, J. M.: Fuero de las Nuevas Poblaciones de Sierra Morena y Andalucía y Legislación complementaria. Ayuntamiento de Guarromán. Jaén, 1992, p. 88. A finales de agosto, Olavide se halla en Sevilla y toma posesión de sus cargos el 3 de septiembre de 1767 en sus Casas Capitulares. Vid.: MATUTE Y GAVIRIA, J.: Anales eclesiásticos y seculares de la muy noble y muy leal ciudad de Sevilla (...). Sevilla, 1887, p. 219.

14 PERDICES DE BLAS, L.: Pablo de Olavide: (1725-1803): el ilustrado. Madrid, 1993, pp. 276277.

Huelva EN SU HISTORIA - 2a ÉPOCA • Vol. 13 • 2010 • [00-00] • ISSN 1136-6877 C Universidad de Huelva 
cería en La Parrilla. ${ }^{15}$ Olavide también exploraba por su cuenta un tercer proyecto al noroeste de Sevilla y en los alrededores de Villanueva, Lora y Constantina, encontrando en este último pueblo a un particular ilusionado en financiarlo, Mateo del Castillo. ${ }^{16}$ Simultáneamente ponía en aplicación las resoluciones reales sobre reparto de tierras baldías concejiles de Sevilla creando una colonia agrícola en las dehesas de Almajar y Prado del Rey en término de Villamartín ${ }^{17}$, próxima a Jerez, y repartiendo entre colonos las tierras de las dehesas de Tablada y Tabladilla. ${ }^{18}$

Estas nuevas poblaciones se regirían por el Fuero de Sierra de Morena. Olavide se hallaba exultante; tenía ahora la posibilidad de realizar, a través de ensayos concretos, su nuevo plan de agricultura tal como lo desarrolló en su Informe a la Ley Agraria; no sólo en Sierra Morena sino en toda la inmensidad de los despoblados de Andalucía. Para ello contaba Olavide con el apoyo del ministro de Hacienda, a quién llega a pedirle, por carta de 8 de mayo de $1768,{ }^{19}$ se le autorice a examinar todas las solicitudes de nuevas poblaciones agrícolas que le lleguen desde Andalucía. Y también con el de Campomanes, que al instante de llegarle la solicitud de Fernando Pérez de Guzmán -firmada en Sevilla en 10 de abril- en 15 de abril recomienda al Consejo de Castilla enviarla a Olavide para que la estudie y dictamine.

Esta idea de extender el plan primitivo de colonización de Sierra Morena a toda Andalucía es exclusiva de la iniciativa personal de Pablo de Olavide. ${ }^{20}$ Esta hipótesis de uno de sus mejores biógrafos, la confirma las indagaciones de Olavide por averiguar los despoblados existentes en el extenso Condado de Niebla. ${ }^{21}$ El proyecto de la nueva población de Guzmanópolis encaja perfectamente en estos planteamientos de Pablo de Olavide; de ahí su apoyo incondicional a Fernando Pérez de Guzmán que pretendía poblar y poner en cultivo unos inmensos baldíos con familias sin tierras que vivían de sus escasos salarios, creando en estas nuevas poblaciones una sociedad nueva donde no imperasen las trabas y los privilegios de la sociedad estamental sino

15 DEFOURNEAUX, M.: Pablo ..., op. cit., p. 145.

16 Carta de Ignacio de Ygareda, Secretario del Consejo de Castilla, a Domingo Alejandro de Cerezo, Regente de Sevilla, Madrid, 18 de julio de 1769. Carta de López Valiente, comisionado real en las Nuevas Poblaciones a Domingo Alejandro Cerezo, Écija, 24 de julio de 1769. Expediente del Real Consejo de Castilla (ERCC), fol. 44 r.-46 r., AFCMS, leg. 705.

17 LÓPEZ RUBIO, J. F.: "Algunas notas a los pleitos entre Villamartín y Prado del Rey (17691886)", en AVILÉS FERNÁNDEZ, M. y SENA MEDINA, G. (Ed.): Las “Nuevas Poblaciones” de Carlos III en Sierra Morena y Andalucía. Córdoba, 1985, pp. 303-310. Vid. también DEFOURNEAUX, M.: Pablo ..., op. cit., pp. 195 y ss.

18 DEFOURNEAUX, M.: Pablo ..., op. cit., pp. 195 y ss.

19 Ibídem, p. 441.

20 DEFOURnEAUX, M.: Pablo ..., op. cit., p. 145.

21 A través del Subdelegado de Nuevas Poblaciones, Juan Gutiérrez Piñeres. Vid.: Expediente. "Niebla, Sevilla, abril, 6,1769. Orden del Asistente de Sevilla para que las Justicias de Niebla le informen los despoblados que aya en su Condado, con jurisdiccion separada, á quien pertenecen, los motivos de su despoblacion, y medios de repararlos y copia del Informe que hicieron dichas Justicias”. El informe se contesta en 20 de mayo del mismo año y se remite copia al duque de Medina Sidonia. AFCMS, leg. 757 . 
el ideario social ${ }^{22}$ que a Olavide le inspiró el pensamiento ilustrado en sus viajes europeos. Aquellas nuevas poblaciones a escala reducida, fueron un "interesante experimento social", un intento de "elevar la condición del campesino" ${ }^{23}$, de convertirlos de inútiles a útiles. ${ }^{24}$

Otro documento que aportamos es todavía más esclarecedor de la relación personal entre Fernando Pérez de Guzmán y Olavide. El 23 de enero de 1770 el duque de Medina Sidonia recibe una carta de Juan Pedro Velázquez Gaztelu, tesorero de sus rentas de la ciudad de Sanlúcar y del coto de Doña Ana, poniéndole en aviso del proyecto de una nueva población en término de Almonte, villa jurisdiccional del estado de Medina Sidonia. El parentesco político de Gaztelu con Fernando Pérez de Guzmán, concuñado, y el intento de este de querer vender un mayorazgo de los bienes de su sobrina María del Carmen Pinto Domonte y el de su mujer, le obliga a efectuar algunas pesquisas, que como fiel administrador del Duque, se las comunica:

"(...) ya ha dias que ha llegado á mi noticia que D. Fernando Perez de Guzman, mi concuñado, havia entrado por persuacion del Asistente de Sevilla en el disparatado empleo de poblador (...). Yo en mi particular ataque cara á cara al D. Fernando el Guzman haziendole patente todos los inconvenientes y menoscabos que se le havian de seguir en su extravagante empresa (...) y he llegado á comprender por lo que le oi que el no es mas que un testaferro que aparenta con su nombre las ideas de algunas casas de comercio adineradas (...)". ${ }^{25}$

22 DEFOURNEAUX, M.: Pablo ..., op. cit., p. 133.

23 DOMÍNGUEZ ORTÍZ, A.: Carlos III y la España de la Ilustración. Madrid, 1988, p. 117.

24 Esta actitud poblacionista de Olavide es una de sus más insistentes preocupaciones: la de ocupar los despoblados con familias humildes que los harían útiles para sí y para la nación beneficiándolos con la agricultura, de ahí que algunos autores definan a Olavide como "agrarista" en contraposición a "fisiócrata". (vid.: PERDICES DE BLAS, L.: "Agronomía y fisiocracia en la obra de Pablo de Olavide", en FUENTES QUINTANA, E. (Ed.): Economía y economistas españoles. Tomo III, La Ilustración, Barcelona, 2000, pp. 275 y ss). Doctrina por lo general muy extendida en el pensamiento ilustrado español y propia del entender de los partidarios de la "nueva agronomía" (vid.: LLUCH, E. y ARGEMÍ, LL., Agronomia y fisiocracia en España (1750-1820). Valencia, 1985, p. 85). Ideas que no sólo compartía Olavide, de las que se hallaba muy imbuido, sino que también estaba determinado más que otro a ponerlas en práctica, como demostraría en sus años de Asistente en Sevilla. Merchán incorpora estos impulsos de Olavide un tercero concerniente al sentido social de la obra pobladora y agrarista que ańade al crecimiento de la riqueza, ya que ésta no tiene sentido sólo por su aumento sino porque al repartir las tierras se crea una sociedad más justa con la creación de pequeños propietarios "útiles", antes jornaleros sujetos a los vaivenes de las cosechas y mendigos casi todo el ańo, o el de unos pelantrines incapaces las más de las veces de cubrir los alquileres de las tierras arrendadas y de introducir los nuevos métodos agrarios que se extendían por toda Europa. Olavide plantea por primera vez una reforma agraria que "aumentaría el número de andaluces que tengan una relación adecuada y estable con la tierra, la cual es su único medio de subsistencia” (vid.: MERCHÁN, A.: La reforma agraria en Andalucia: el primer proyecto legislativo: (Pablo de Olavide, Sevilla, 1768). Universidad de Sevilla, Sevilla, 1997, pp. 43 y 94.

25 La carta está fechada en Sanlúcar de Barrameda en 16 de enero. AFCMS, leg. 2374. 
El contenido de la carta es sumamente explícito de la directa intervención de Olavide, por "persuasión", en el proyecto de Fernando Pérez de Guzmán de levantar una población agrícola en los enormes baldíos de Almonte ${ }^{26}$. Fernando Pérez de Guzmán debió acudir a las concurridas, frecuentes y famosas tertulias organizadas por Olavide en su domicilio de los Reales Alcázares ${ }^{27}$, donde se reunía lo más selecto de la ilustración sevillana y se deliberaban y comentaban los proyectos de Olavide para Sevilla, o del Gobierno "ilustrado" para la nación, sobre el teatro, los nuevos "philosofos", la economía "política", etc.; tertulias donde Olavide, sobre todo, captaba apoyos y seguidores a sus ideas o planes concretos. En estas tertulias se fraguaría, pensamos, el proyecto Guzmanópolis entre Pablo de Olavide, Fernando Pérez de Guzmán y sus amigos comerciantes ${ }^{28}$, de ser cierto la información que nos facilita el sanluqueño Juan Pedro Velázquez Gaztelu; pero también a Mateo del Castillo para poblar en Constantina, como hemos visto; o a Miguel Gijón y León, hombre adinerado e ilustrado, que acabó comprando tierras en la costa granadina para fincas agrícolas experimentales y que sería nombrado subdelegado general para las Nuevas Poblaciones, la mano derecha de Olavide en Sierra Morena. ${ }^{29}$

Las denuncias de los contratistas que traían los colonos alemanes y suizos, Thurriegel -agosto de 1768-- y Yauch - marzo de 1769 - dirigidas al Consejo de Castilla sobre la mala situación de las colonias, provocan que este Consejo forme una Junta para estudiar tales denuncias, envía a los consejeros Ricardo Wall y Devreux y Francisco Carrasco y Montero (Marqués de la Corona) para una visita de inspección secreta, nombra un comisionado con plenos poderes, Pedro José Pérez Valiente ${ }^{30}$ y, en último lugar, destituye provisionalmente a Pablo de Olavide de la Superintendencia de las Nuevas Poblaciones. ${ }^{31}$

26 La persuasión era "la regla maestra" de Olavide para aplicar y extender sus ideas, proyectos y reformas. Vid. PERDICES BLAS, L.: Pablo de Olavide ..., op. cit., pp. 285 y ss. y 518 y ss.

27 Historiadores del fenómeno de la Ilustración y biógrafos de Pablo de Olavide, han dedicado muchas páginas a analizar el fenómeno de las "tertulias" dieciochescas, como centro y motor de la expansión de las ideas ilustradas y germen de las futuras sociedades de amigos del País. Entre otros DEFOURNEAUX, M.: Pablo ..., op. cit., p. 216; y especialmente AGUILAR PIŃAL, F.: La Sevilla de Olavide, 1767-1778. Sevilla, 1995, pp. 25 y 151. Estas tertulias olavidianas se dan también en su casa palacio de La Carolina, donde acoge también a ilustres viajeros, como fue el caso, entre otros, del duque de Alba.

28 La compra de tierras por la burguesía sevillana enriquecida por el comercio americano y europeo es un hecho constatado en todo el siglo XVIII y que el precio de compra era muchos más alto que el de venta. La adquisición de terrenos a través del establecimiento de nuevas poblaciones agrícolas sería una nueva posibilidad de la burguesía adinerada por el comercio. Vid. GAMERO ROJAS, M.: "La nobleza titulada sevillana y su participación en el mercado de la tierra de 1700 a 1834"; en Coloquio Internacional Carlos III y su siglo. Madrid, 1990, pp. 795-818.

29 DEFOURNEAUX, M., op. cit., p. 139.

30 Ibídem, pp. 148-151.

31 Real Cédula, Aranjuez, 6 de abril de 1769, B. N., MSS/11265/82. La inspección debe durar tres meses, pero hasta el 24 de agosto no es repuesto Olavide en su cargo de Superintendente de las Nuevas Poblaciones. Vid. DEFOURNEAUX, M., op. cit., p. 154. 
Ante las reiteradas insistencias de Fernando Pérez de Guzmán al Consejo de Castilla para que tome una resolución a la solicitud de su proyecto de nueva población, le contesta el secretario del Consejo, Ignacio Estéban de Ygareda, que "su proyecto con otros de igual naturaleza pasaron á Pérez Valiente de orden del Consejo, para que oyendo á los interesados se informase de las partes". ${ }^{32}$ Fernando Pérez de Guzmán no recibe contestación de Valiente y se persona en La Parrilla donde le entrega en mano el 24 de junio una nueva misiva solicitándole permiso "para empezar a construir la nueva población por ser tiempo adecuado y tener fondos suficientes". ${ }^{33}$ Tampoco recibe respuesta.

Pablo de Olavide sale indemne tras la visita del comisionado regio y vuelve a La Peńuela en julio de 1769, pero en el Consejo se había producido cierta ruptura en la antigua férrea unanimidad en el proceso para levantar el proyecto de Nuevas Poblaciones de Sierra Morena y sobre los métodos de su máximo responsable. ${ }^{34}$ Como afirma Defourneaux, el grupo Aranda-Campomanes-Olavide había perdido cohesión y se traslucía un fondo político en estos últimos avatares que anunciaban el devenir inmediato del propio Olavide, y se descubría, a su vez, que una verdadera conspiración se alzaba contra las nuevas poblaciones de Sierra Morena. ${ }^{35}$ Esta crisis provoca desavenencias entre el Conde de Aranda, Floridablanca, Campomanes y Grimaldi y que acabaría con la destitución de Aranda como Presidente del Consejo de Castilla en $1773 .{ }^{36}$ Los tres se volvieron más prudentes y en el Consejo de Castilla se tomaron ciertas precauciones no sólo para Sierra Morena sino para los proyectos de nuevas poblaciones agrícolas en curso y de las posibles futuras solicitudes. El proyecto Guzmanópolis sufre estas tensiones y desde el Consejo de Castilla se ordena en 18 de julio de 1769 que la tramitación de su expediente pase a ser llevada por el Regente de la Real Audiencia de Sevilla. ${ }^{37}$ Un año después, Pablo de Olavide recibe del Consejo de Castilla unas nuevas Instrucciones para el gobierno de las nuevas poblaciones de Sierra Morena y Andalucía que, entre otras cuestiones, limita su ámbito geográfico al establecido en ese momento y no podrá extenderse con nuevas colonias. ${ }^{38}$ Sus am-

32 Carta de Fernando Pérez de Guzmán a Pedro José Valiente, fechada en Sevilla en 31 de mayo de 1769, ofreciéndose para ser escuchado y seguir con el expediente. ERCC, fol. 43 r.

33 ERCC, fol. $44 \mathrm{r} .-44 \mathrm{v}$.

34 El manuscrito ${ }^{\circ} 10.733$ de la Biblioteca Nacional es el expediente que se forma en el Consejo de Castilla tras las visitas; contiene los dictámenes, votos particulares y alegaciones de los visitadores y de los fiscales y el borrador de la futura Instrucción de 1770. Campomanes todavía defiende con firmeza la actuación de Olavide.

35 DEFORNUEAUX, M.: Pablo ..., op. cit., pp. 156-157.

36 PERDICES DE BLAS, L.: Pablo de Olavide: (1725-1803)...., Madrid, 1993, pp. 353-354.

37 Carta de Ignacio de Ygareda, Secretario del Consejo, a Domingo Alejandro de Cerezo, Regente de Sevilla, para que se haga cargo de los expedientes de las nuevas poblaciones promovidas por particulares, ERCC, fol. 45 r. 45 v. Carta Pedro José Pérez Valiente a Domingo Alejandro de Cerezo, remitiéndole los expedientes de Fernando Pérez de Guzmán y de Mateo del Castillo, Écija, 24 de julio de 1769, ERCC, fol. 47 r. $-47 \mathrm{v}$.

38 En este aspecto, influyó las alegaciones del Marqués de la Corona en la Junta que denunció que Olavide obraba a su antojo, interpretaba a su manera el Fuero y si por él fuera hasta Cádiz hubiera "llegado poblando los caminos y fertilizando los baldios". DEFOURNEAUX, M., op. cit., p. 162. Desde luego que 
biciones de llevar su "plan de agricultura", de una verdadera reforma agraria a toda Andalucía quedaron truncadas para siempre. ${ }^{39}$ El proyecto Guzmanópolis sufriría con esa severa amputación, pues, como sabemos, era su principal adalid. Pablo de Olavide no volverá a intervenir en este proyecto ilustrado en tierras de Huelva; pero dejó su huella emprendedora e innovadora y también su tesón en muchos hombres, entre ellos, Fernando Pérez de Guzmán, que luchará hasta su muerte por el proyecto de la nueva población Guzmanópolis.

\section{El proyecto Guzmanópolis.}

No disponemos de información suficiente sobre el "proyectista" ilustrado Fernando Pérez de Guzmán para rehacer siquiera una pequeña biografía. A lo largo de extensa documentación consultada sólo aparecieron referencias personales sobre su vida íntima y profesional, pero poco más. Era vecino de la ciudad de Sevilla, pero sus antepasados inmediatos procedían de la provincia de Badajoz, donde establecieron un mayorazgo sobre bienes raíces extendidos sobre varios pueblos. En 1768 era Teniente Coronel del Regimiento de Milicias de la ciudad de Sevilla, aunque sin sueldo; al frente de este regimiento moriría en el campo de batalla en el Rosellón francés en el verano-otoño de 1794. Quizás esta condición de militar le proporcionó los primeros contactos con el recién llegado a Sevilla, Pablo de Olavide, Intendente de los Ejércitos de Andalucía. Estuvo casado dos veces. Su primera mujer fue Catalina García Fernández de Poedo y Novoa, natural y vecina de Sanlúcar de Barrameda, viuda desde 1755 de Pedro Domonte y Pinto; esposa que fallecería en las navidades de 1769-1770. De su segunda esposa, sólo conocemos su apellido, Osorno Catalán, hermana de la condesa de Campo Alange. Fernando Pérez de Guzmán conocía bien los terrenos que pretendía poblar, pues durante los años de 1757 a 1769 fue arrendatario de los pastos de la dehesa de las Casas en el interior del Coto de Doña Ana. En el proyecto de Guzmanópolis, Fernando Pérez de Guzmán no actuaba sólo, sino que fue el testaferro de una sociedad mercantil creada al efecto y formada por comerciantes e industriales de la ciudad de Sevilla, grupo del que nada conocemos, sólo de su existencia por noticias indirectas.

Con fecha 10 de abril de 1768 y desde Sevilla, Fernando Pérez de Guzmán el Bueno remite al Supremo Consejo de Castilla un proyecto de poblar dos leguas de término de Almonte en el sitio conocido como El Rocío, al modo de Sierra Morena y con otras condiciones particulares. La solicitud va acompañada con sendas cartas de remisión, también desde Sevilla y con la misma fecha, dirigidas una al Rey y la otra al fiscal de dicho Consejo, Pedro Rodríguez Campomanes. ${ }^{40}$

no le faltaba razón.

39 “(...) las Instrucciones de 1770 no dejan de arruinar el sueńo que había concebido: hacer de los nuevos establecimientos un modelo y un punto de partida para transformar gradualmente todo el campo andaluz, implantando en las dehesas y los baldíos entregados a la ganadería extensiva, el sistema de cultivo y apropiación del suelo aplicado primero en Sierra Morena y extendido por su iniciativa a las "Colonias de Andalucía". DOFOURNEAUX, M., op. cit., p. 172.

40 (ERCC), fol. 2 r. -6 r. 
En la misiva dirigida al Monarca, Fernando Pérez de Guzmán justifica sus intenciones personales en este proyecto con tres razones fundamentales. En primer lugar, por su inclinación al "Real Servicio y amor nacional" siguiendo en esto la línea trazada por sus "antepasados", haciendo clara referencia al fundador de la Casa de Niebla; ${ }^{41}$ continua argumentando que pretende con su proyecto una doble intencionalidad tanto en el "augmento de la Agricultura", fin primordial de las nuevas poblaciones de Sierra Morena diseñado por el Consejo, así como en el "aumento de Rentas Reales", hasta ahora inexistentes en aquellas tierras que se pretende poblar, incultas y abandonadas; en tercer lugar que esta "empresa", impregnada sólo del "bien patriotico" del solicitante, no debe pasar desapercibida por la "alta Ilustración” del Supremo Consejo.

Con muy similares argumentos pretende ganarse Fernando Pérez de Guzmán el favor y el apoyo a su proyecto del Fiscal del Consejo, con un discurso donde se considera a si mismo como hombre de bien que quiere conservar y aumentar su honor como "poblador", desechando otras opciones al uso en la época como la guerra o "las letras", y de que éstas últimas más que aumentarlo "lo malisan”, afirma tajantemente Fernando Pérez de Guzmán. Finaliza con un párrafo sutilmente elogiador para el destinatario:

"España debe mucho á su Ylustrisima, es inmenso el bien que le hace y lavor general que aclama su merito, me anima á mi para dirigirle la adjunta representación, á fin de que se sirva examinarla, esperando de su amor Patriotico, que si encuentra alguna solidez en mi pensamiento lo haga presente á la Ilustración y al Consejo y lo apoye vuestra Seńoría Ilustrisima con la eficacia que tiene quando conoce el bien nacional.”

Es indudable que el solicitante conocía bien las ideas y pensamientos de sus interlocutores, de las personas que determinarían la validez y aceptación de su proyecto de nueva población; en otras palabras, de las directrices emprendidas por el gobierno para el fomento de la agricultura. Como observamos aparecen en los textos vocablos tales como amor y bien nacionales, amor patriótico, poblador, aumento de la agricultura y, por supuesto, ilustración; voces que nos sumergen de lleno en la amplísima producción literaria y científica que produjo la segunda mitad del Siglo de las Luces. ${ }^{42}$

La primera misiva, por vía del Consejo de Castilla, va dirigida al monarca con toda la clarividencia de que Fernando Pérez de Guzmán, al igual que el resto de ciu-

41 En otra parte de la solicitud hace referencia a "su hermano", en aquel ańo Caballerizo Mayor del Rey, Pedro de Alcántara Pérez de Guzmán el Bueno, XIV Duque de Medina Sidonia. Esta rama sevillana del linaje Pérez de Guzmán, bastarda con seguridad, fue fundada en el siglo XIII por Alvar Pérez de Guzmán, Alguacil Mayor de Sevilla, que se extingue en 1394 y es sucedida en sus intereses señoriales en Andalucía por la Casa de Zúńiga; vid. LADERO QUESADA, M. A.: "Los seńoríos medievales onubenses", en Huelva en la Andalucía del siglo XV. Huelva, 1986, p. 68. Este Alvar Pérez de Guzmán era hermano de Alfonso Pérez de Guzmán El Bueno, primer señor de Sanlúcar de Barrameda; vid. BARRANTES MALDONADO, P.: Ilustraciones de la Casa de Niebla, RAH, Madrid, 1857, t. IX, p. 273. Su árbol genealógico completo en SÁNCHEZ SAUS, R.: Linajes sevillanos medievales. Sevilla, 1991, vol. II, p. 368.

42 DOMÍNGUEZ ORTIZ, A.: Carlos III y la España de la Ilustración. Madrid, 1988, p. 116. 
dadanos de Espańa, piensa que es el rey el primero que trata de fomentar la riqueza general del país, la cabeza visible del movimiento reformador, de quién emanan las órdenes incuestionables que ejecutaran sus ministros. Fernando, fiel vasallo y buen patriota, sigue las directrices de su rey para el fomento de la agricultura; pero además contribuirá al aumento de la real hacienda con los beneficios de la producción y el comercio que surgirá de la nueva población agrícola. Acababa de iniciarse las primeras colonias de Sierra Morena, sin resultados aún, pero Fernando Pérez de Guzmán tiene confianza plena en este proyecto "en vista de las savias providencias que el Consejo ha dictado para las nuevas poblaciones", afirmaba en su misiva no exenta de querer ganarse también los favores de un Consejo que dictaminaría sobre el proyecto y daría el último paso de presentarlo a real aprobación.

Pero también parece que Fernando Pérez de Guzmán conoce el peso de la autoridad de Campomanes en el propio Consejo y la confianza que merecía al monarca en todos sus proyectos reformistas. En este caso que nos ocupa, fue Campomanes el redactor del llamado Fuero de las Nuevas Poblaciones de Sierra Morena para asentar a varios miles de alemanes y flamencos. ${ }^{43}$ Fernando Pérez de Guzmán reconoce en su carta lo que debe Espańa al Fiscal del Consejo por su labor en favor de las reformas emprendidas para la modernización de las estructuras productivas, y con franca emulación, Fernando quiere contribuir a esta labor general emprendida por el gobierno como "poblador" y poner en producción unas tierras incultas hasta ahora. Esta es la gracia y favor que solicita.

En una simple apreciación se nos apetece pensar que la solicitud para la nueva población es un documento muy breve para un proyecto de tal envergadura, pero a pesar de esta sumaria exposición, el documento esconde cierta amplitud de objetivos.

Observamos, en primer lugar, que la elección del lugar escogido se halla en el centro de un amplio territorio de más de 50 leguas cuadradas sin ninguna entidad de población, por lo que está justificada, según Fernando Pérez de Guzmán, la ocupación de dos leguas cuadradas para "poblarlas", siguiendo el modelo que se estaba empleando en las de Sierra Morena. Pero esta justificación de ocupar un terreno por despoblado fuera de la demarcación de Sierra Morena no estaba recogida en la Real Cédula e Instrucción de 25 de junio y 5 de julio de 1767 respectivamente. ${ }^{44}$

De tan extenso despoblado, pide Fernando Pérez de Guzmán dos leguas de terreno, es decir, aproximadamente unas 3.105 hectáreas, ${ }^{45}$ y donde quedaría comprendida la

43 Real Cédula de Su Magestad, y Señores de su Consejo, que contiene La Instrucción, y fuero de poblacion, que se debe observar en las que se formen de nuevo en la Sierramorena con naturales, y estrangeros Católicos. Año de 1767. En Madrid, en la Oficina de Don Antonio Sanz, Impresor del Rey nuestro Señor, y de su Consejo. En su página A 2, v. se cita que dicha Instrucción se ejecutó de orden de Pedro Rodríguez Campomanes. En la Novísima Recopilación, Titulo XXII, Libro VII, Ley III, correspondiente a dicha Real Cédula de 5 de julio de 1767 e Instrucción inserta de 25 de junio del mismo año con el título Reglas para las nuevas poblaciones de Sierramorena; y fuero de sus pobladores solo se cita en su párrafo primero que fue elaborada por el Fiscal de la Superintendencia General de la Real Hacienda.

44 El capítulo 58 dictaba que el Superintendente podría admitir las propuestas de las personas acaudaladas que quisieran "entrar á poblar de su cuenta algun sitio de la Sierramorena".

45 En los primeros momentos creíamos que eran dos leguas cuadradas, unas 12.421 hectáreas, pero 
ermita de Ntra. Sra. del Rocío, para "poblarlas del modo de Sierra Morena” repartiendo a cada colono 50 fanegas $^{46}$, (29,72 hectáreas), como efectivamente se legislaba en las Instrucciones de las nuevas poblaciones de Sierra Morena en su capítulo $8 .{ }^{47}$ Con esta cantidad de terreno, la nueva población podría acoger a numerosos colonos, extraídas estas personas, según solicita Fernando Pérez de Guzmán, de "donde las encuentre", sin concretar más; mientras que para Sierra Morena se especifica en sus capítulos 28, 30 y 72 ciertas normas para la admisión de colonos españoles. ${ }^{48}$

El modelo de Sierra Morena sigue presente en las siguientes peticiones. Las relativas a que las dos leguas de terreno deben cerradas y acotadas para el uso y disfrute exclusivo de dichos colonos, no permitiéndose ningún aprovechamiento silvopastoril por los vecinos comarcanos de este extenso terreno. Las preeminencias y exenciones que deberán disfrutar los colonos citadas en el documento son las contenidas en los capítulos 19, 55, 56 y 57 relativos a la moratoria de diez de ańos en el pago de todo arbitrio, diezmo y canon de tierras a la Real Hacienda, pero con la salvedad de que los diezmos que se impondrán en el futuro serán regalía del promotor del proyecto, como se estipula en el capítulo 58. Y en cuanto a la administración de justicia de las colonias, ésta quedará bajo la tutela del Superintendente y Sala Primera del Supremo Consejo hasta el total establecimiento y autonomía de dicha colonia, en que pasará a determinarse por la justicia ordinaria, como dispone su capítulo 52. Esta nueva colonia se regirá y estará amparada por las mismas leyes y disposiciones que las de Sierra Morena.

Como anunciábamos, Fernando Pérez de Guzmán incluye en el proyecto unas condiciones particulares para su ejecución. La primera es la concesión en propiedad hereditaria de dos caños desaguaderos existentes dentro del terreno demarcado, sin más especificación, y que se pretenden convertir en un solo canal " $a$ veneficio del comercio" de los pueblos comarcanos; idea ésta muy en consonancia con los teóricos y proyectistas ilustrados. La construcción de canales o "caminos artificiales" para el transporte de mercancías y para el riego de tierras fue una de las medidas propuesta por el comisionado real Bernardo Ward tras reconocer la extensa geografía española ${ }^{49}$,

al estudiar detenidamente el terreno demarcado comprendimos que era un cuadrado de una legua de lado.

$46 \mathrm{La}$ medida de la fanega que hemos adoptado es la de 0,5945 has., siguiendo a OJEDA RIVERA, J. F.: Organización ..., pp. 27-28.

47 "A cada vecino poblador se le dará, en lo que llaman navas ó campos, cinquenta fanegas de tierra de labor por dotación y repartimiento suyo (...)”. Novísima Recopilación de las Leyes de España, Título XXI, Libro VII, Ley III.

48 Se trata de regular los casamientos con naturales fuera de los reinos andaluces y provincia de la Mancha y de preferencia en la admisión en las colonias de los naturales recogidos en los hospicios de Córdoba, Jaén, Sevilla y Almagro.

49 Proyecto económico. Bernardo Ward. Edición y estudio preliminar de Juan Luis Castellano Castellano. Madrid, 1982, p. 63. La obra acabada en 1762, no se publicó hasta 1779, por orden de Campomanes, que sí llegó a conocer el manuscrito. Vid. SARRAILH, J.: La España ilustrada de la segunda mitad del siglo XVIII. Méjico, 1974, p. 644. 
la idea práctica de alguna revista ${ }^{50}$ o de los escritores ilustrados de aquellos ańos como Carlos de Simón ${ }^{51}$, y del propio Arriquívar algunos años después. ${ }^{52}$ En segundo lugar y para financiar el proyecto de "empresa tan grande", Fernando Pérez de Guzmán necesita que el Consejo le permita vender una serie de bienes inmuebles vinculados a su mayorazgo y prioridad en el cobro de un préstamo de 6.300 ducados que le debe el ayuntamiento de Sevilla. Por último y ejecutado el proyecto de esta nueva población, se le otorgará el grado y sueldo de coronel del ejército real..$^{53}$

La instancia de Fernando Pérez de Guzmán llega al Fiscal del Supremo Consejo el 15 de abril y en este mismo día emite su informe que es aceptado por el Consejo. Propone el Fiscal que se remita dicho proyecto al Asistente de Sevilla, Pablo de Olavide, con varias instrucciones, entre ellas que se reconozca el terreno por peritos, si es baldío, si algún particular tiene propiedades en él, si algunos pueblos tienen comunidad sobre dicho terreno, si puede resultar algún perjuicio a tercero si se efectúa la nueva población, el número de vecinos que intenta establecer, los efectos y valor de lo que pretende vender Fernando Pérez de Guzmán y todo lo que se le ofrezca al Asistente teniendo presente el fuero de población de Sierra Morena. ${ }^{54}$

En primer lugar, Pablo de Olavide solicita a Fernando Pérez de Guzmán que hiciese "formal señalamiento del sitio" elegido para la nueva población, para lo cual le remite a Olavide con carta fechada en Sevilla el 14 de julio de 1768 un plano detallado (vid. Plano $\mathrm{n}^{\circ} 1$ del Apéndice), con un terreno demarcado de 3.500 fanegas ${ }^{55}$ o 2.081 hectáreas (una legua cuadrada), que es al final el terreno que solicita y no el primitivo de las dos leguas ${ }^{56}$, con sus linderos especificados: norte, baldíos de la villa de Almonte y coto del Rey en término de Hinojos; sur, madre de las Rocinas y coto de Doña Ana; este, coto del Rey, y oeste, baldíos de la villa de Almonte. La ermita del Rocío queda incluida junto a su lindero sur. Este plano con el interrogatorio

50 "Discurso sobre el modo de regar los campos", en Discursos mercuriales, no 13,5 de mayo de 1756, pp. 653-680. Cit. en RAMÍREZ, B. A.: Diccionario de Bibliografia Agronómica de toda clase de escritos relacionados con la agricultura. Madrid, 1988, p. 549.

51 Papel instructivo que escribe Don Carlos de Simón, Pontero del Consejo de S. M. y Alcalde de Casa y Corte, para los que quieran interesarse en la compañia de navegación de los rios Tajo, Guadiela, Manzanares y Jarama, que se ha de formar bajo la real protección de S. M..... Madrid, 1756, por Pérez de Soto. Cit. en RAMÍREZ, B. A., Ibídem, pp. 310-311.

52 ARRIQUIVAR, N. DE.: Recreacion politica. Estudio preliminar y edición a cargo de Jesús Astigarraga y José Manuel Barrenechea, Bilbao, 1987. Carta VII, p. 150.

53 Fernando Pérez de Guzmán en el año 1768 era Teniente Coronel del Regimiento de Milicias de la ciudad de Sevilla, según él mismo lo expresa en las solicitudes del proyecto de nueva población. ERCC, fol. 1 r., 4 r. y ss.; aunque al parecer sin sueldo, según manifestaba su concuñado, Juan Pedro Velázquez Gaztelu, al duque de Medina Sidonia en carta de 16 de enero de 1770. AFMS, leg. 2.374.

54 ERCC, fol. 7 v. -8 r.

55 ERCC, fol. 9 r. -9 v.

56 Informe de Pablo de Olavide de 6 de octubre de 1768, en su párrafo 10 dice textualmente: "En cumplimiento de esta resolucion del Consejo dispuse: que por el dicho don Fernando Perez de Guzman se hiciese formal señalamiento del sitio en que pretendía establecer la nueva poblacion; hizolo asi presentando un mapa de 3.500 fanegas de tierra que eligio en el sitio del Rozio termino de la villa de Almonte explicando sus linderos". ERCC, folios 33 r.-40 v. 
propuesto por el Fiscal del Consejo lo remite Olavide al corregidor de Almonte el 15 de julio de 1768 .

En 4 de agosto de 1768, el ayuntamiento de Almonte efectúa los autos requeridos por el Intendente de Sevilla en sus cartas requisitorias de 15 y 30 de julio de este año. El día anterior, una comisión compuesta por cuatro peritos del pueblo, Cristóbal de Garfías, de 72 años; Francisco Moreno, de 56 años; Román Barrera, de 60 años; Lucas Lozano, de 48 años; el corregidor, Pedro González Hidalgo; y el síndico procurador general Pedro de Cabrera, hicieron "pronta y prolija visita á los sitios interesados" 57 , determinando que el terreno que ocupan las 3.500 fanegas está compuestos por los parajes Llano de la Cruz, Ruidero, Pico de las Matas (norte), Boca de la Rocina, Rincón (sur), El Cañuelo (este) y Los Montes (oeste); que la calidad de las tierras es “inútil por ser arenoso todo el terreno" y habiéndose hecho algunas catas no se halló barro alguno; no obstante se encontró en algunos parajes "aunque pocos en alguna tierra pero mui inferior, su situación en el dia esta sin cultibo". Estos peritos continúan informando que el terreno tiene "montes por las mas partes y por otras esta yermo"; y que hay abundancia de aguas porque en la mayor parte del año se inundan muchos sitios de estos parajes elegido para la nueva población, por lo cual nada pueden producir, salvo que sean "algunas gamonitas, atarafes y otros yervazos que se crian en los friales y sitios humedos". En otro orden del cuestionario remitido, afirman que dicho terreno es baldío de la villa de Almonte, ${ }^{58}$ es decir, terrenos de aprovechamientos comunales bajo control del concejo municipal. Concluyen los peritos el interrogatorio exponiendo que dicho terreno forma parte de los baldíos que aprovechan para pastos de ganados de los vecinos de las villas de Almonte y de Hinojos de forma mancomunada; costumbre cierta de origen medieval y que ha pervivido en siglos posteriores. En la segunda mitad del XVIII esta hermandad de pastos entre Almonte e Hinojos afectaba a los terrenos conocidos como Los Montes, Rincón y Cañuelo, baldíos de la villa de Almonte, y a la conocida por Marisma Gallega, respectivamente, para uso exclusivo

57 ERCC, fol. 11 r.-32 v. Extenso documento por lo que ofreceremos sólo información puntual.

58 Atendiéndonos al Catastro de Ensenada y en los datos porcentuales que publicaron OJEDA RIVERA (Op. cit.) y F. NÚNEEZ ROLDÁN (En los confines del Reino. Huelva y su tierra en el siglo XVIII. Sevilla, 1987), aunque con leves diferencias, la superficie cultivada en el término de Almonte rondaba el 12\% del total de la superficie catastrada (35.699 hectáreas), mientras que las tierras no cultivadas se aproximaban al 88\% de su extensión. De éstas, 4.786 hectáreas se destinaban a encinar, pinar y dehesas; 23.962 hectáreas a baldíos de aprovechamientos comunales y declarando sólo como “inútiles” unas 2.660 hectáreas. Si tenemos en cuenta que la extensión actual del municipio es de 86.568 hectáreas, los peritos dejaron por catastrar el $70,17 \%$ de las tierras, un porcentaje muy elevado e incomprensible al incluirse en las mediciones 26.622 hectáreas de terrenos baldíos e inútiles. Aunque Ojeda Rivera propone varias razones e hipótesis de esta grave imprecisión catastral (Op. cit., pp. 27-29), nos parece aún excesivo el error detectado. Pero volviendo a la superficie catastrada podemos apreciar que las tierras de la nueva población ocupaban el 8,68\% de las tierras baldías de Almonte. Porcentaje relativamente pequeño con respecto a las tierras comunales, pero la extensión de esta nueva colonia agrícola de 2.081 hectáreas suponía el 48,48\% con respecto al total de la tierra cultivada y el $43,46 \%$ en relación a la tierra ocupada con arbolado productivo en todo el término; cifras que indican la importancia de la extensión del terreno elegido para poblar. Queremos indicar con estos datos la posible apreciación subjetiva que los habitantes de Almonte podían tener de la extensión destinada a la nueva población. 
de los vecinos de ambos pueblos. Los ganados de estos vecinos sólo podían pastar de día, recogiéndose y retirándose por la noche a sus propias delimitaciones ${ }^{59}$, cuya linde era el arroyo de Santa María. Además de la importancia de las cabañas ganaderas de los naturales de Almonte ${ }^{60}$ e Hinojos, ésta última villa permitía el pasturaje de muchos hacendados que se avecindaban y tenían casa abierta en Hinojos. Ante esta circunstancia y a la situación de los futuros terrenos pretendidos para la instalación de la nueva colonia agrícola, los peritos puntualizaron que "no dejaria de seguirse algun perjuicio á las dos villas dichas en quanto que tendrian sus ganados menos livertad", con clara referencia al paso de unos parajes a otros y a la importante reducción de la extensión de pastos disponibles.

En el penúltimo punto del interrogatorio, afirman los peritos que nadie tiene "dominio" sobre dicho terreno salvo "el solariego de la Casa de Medina Sidonia". Fernando Pérez de Guzmán contesta al Asistente de Sevilla sobre este punto afirmando que " $E l$ sitio es valdio igualmente que todas las marismas, en las que bajo de este seguro concepto la Casa de Medina Celi se jacta de tener privilegio para cortar almarjos, lo que no se le hubiera concedido si fuera de dominio particular; por otra parte es notorio que en la Andalucia no hay señores Solariegos ni este privilegio (aun quando alguno lo tuviese) dexaria de estar abolido por el no uso"; respuesta que conlleva por parte de Fernando Pérez de Guzmán un conocimiento exacto de la formación histórica de los señoríos andaluces y de su situación dentro del ordenamiento jurídico de la época ${ }^{61}$. Efectivamente, la compra de la jurisdicción civil y criminal de la villa de Almonte que efectúa primero los condes de Niebla y remata luego la casa ducal, se alcanza sobre diversos lotes que poseían los herederos de Alvar Pérez de Guzmán, (primer señor de Almonte desde 1335), a lo largo del siglo XV y que concluye definitivamente en mayo de $1499 .{ }^{62}$ Sin embargo, los abogados y procuradores, a instancia de la Duquesa se personan en el expediente el 17 de noviembre de 1769 alegando que el sitio solicitado para la nueva población "es propio de mi Casa y Mayorazgo" y adjunta la toma de posesión de la villa de Almonte, coto de Dońa Ana y de la dehesa de Los Arrendadores efectuada por el duque Don Pedro por muerte de su padre D. Domingo en el año 1739. No obstante estos documentos, el procurador del Duque alega en el expediente, con

59 CARMONA RUIZ, M. A.: La ganadería ..., op. cit., p. 234.

60 Los terrenos de la nueva población, parajes de El Rincón y Cańuelo principalmente, y los terrenos litigados secularmente a la casa de Medina Sidonia, que se comprendían desde el Cańo de la Raya hasta la Madre de las Marismas (unas 8.000 has. dentro del actual Parque Nacional de Doñana) eran destinados sobre todo a pastos libres del ganado vacuno, yeguar, lanar y porcino; con abundantes hatos, zahurdones y cabañas en estos terrenos. La cabaña ganadera de Almonte en el ańo 1752 era una de las principales de la actual provincia; con 2.673 cabezas de vacuno era la segunda tras Valverde; con 4.067 de porcino era la segunda tras el Cerro, siendo la primera en cuanto a la cría caballar, 516 cabezas (Vid. NÚNÉEZ ROLDÁN, F: En los confines ..., op. cit., pp. 472-474).

61 LADERO QUESADA, M. A.: Andalucía en el siglo XV. Estudios de Historia Politica. Madrid, 1973 , p. 2 y ss.

62 Todo el proceso de compra del lugar de Almonte puede verse en AFCMS, legajo 697. También en CASTRILLO DÍAZ, M. C.: Doñana nombre a nombre. Estudio de la toponimia del Parque Nacional de Doñana, Huelva, 2000, pp. 206-213. 
pedimento de 29 de noviembre, que en término competente presentará los títulos solariegos en el Condado de Niebla y en El Rocío. ${ }^{63}$ Estos títulos jamás se exhibieron en el expediente y desconocemos si las razones se debieron a pérdida documental o que realmente nunca existieron, hipótesis ésta última que viene avalada por dudas muy serias que emanan de los múltiples pleitos que la villa de Almonte ha mantenido con la casa ducal por al antiguo coto de Doña Ana, el último en $1869^{64}$, y que nunca presentaron los títulos de propiedad requeridos por los abogados de Almonte. El hecho es que este tema nunca ha sido estudiado en profundidad por los historiadores. De lo que no existe duda alguna es que los terrenos demarcados y pretendidos para la nueva población eran baldíos de Almonte, salvo la dehesa de Los Arrendadores. ${ }^{65}$ En cuanto al privilegio de la casa de Medinaceli, está hoy muy bien documentado los numerosos pleitos que ambas casas nobiliarias mantuvieron por el aprovechamiento de los almarjos o armajos a lo largo del Antiguo Régimen.

El cabildo de Almonte representado por su alcalde mayor, el alférez mayor, el síndico procurador general y común del vecindario, reunidos el 4 de agosto ${ }^{66}$, emitieron su informe al Asistente de Sevilla, Pablo de Olavide; informe prácticamente coincidente con el emitido por los peritos nombrados. Comentan la inutilidad del terreno, arenoso, pero inciden en su incapacidad de producir trigo, tan sólo centeno y cebada con la condición de dejar "descansar la tierra por mucho tiempo para que pueda volverlos á producir", afirmaban. Esta era la práctica habitual en la sembradura de secano del Almonte de mediados del XVIII, sistema de cultivo conocido como "las rozas" ${ }^{67}$ También afirmaban que había algunos parajes, pero de corta extensión, con tierra de inferior calidad que podrían producir trigo laboreando con cuidado y con mucho estiércol. Se describe en el informe un paisaje llano y arenoso hasta una profundidad de vara y media $(124,5 \mathrm{cms}$.), poblado de acebuches frondosos, guardaperos, lentiscos, parrones silvestres, atarajes, jaguarzos blancos, brezos, etc.; este terreno llano -dicen- está la mayor parte del año inundado por dos motivos, por no "tener huida las aguas" o bien porque "reboza" el arroyo de Santa María. Estas tierras inundables y próximas a este arroyo se pueden sembrar pinares y viñas, pero no trigo "á menos que

63 ERCC, fol. 75 r.- 85 v.

64 Incluso en tiempos de la Primera República, los llamados "Terrenos de la Cuestión” se declararon propiedad del Ayuntamiento (Vid. Acta Capitular de 24/05/1873). El pleito se zanjó definitivamente a favor del marqués de Villafranca por Resolución del Ministerio de Hacienda del año 1882, como se recogen en las actas capitulares de 20 de julio de 1882 y 4 de abril de 1883.

65 Incluso si admitiésemos como verdaderas las copias simples efectuadas en los ańos 1749 y 1815, que se conservan en el AFCMS sobre la concesión regia al señor de Sanlúcar de las dehesas de El Carrizal y de La Figuera -el antiguo Bosque de las Rocinas - dada en el cerco de Algeciras en 12 de octubre de 1309, la linde norte no incluye a la ermita del Rocío -documento más antiguo por ahora que cita esta famosa construcción-- ni a los parajes de El Rincón y Cañuelo, sino que queda deslindado por el arroyo de las Rocinas, Madre de las Marismas y Caño Marín, límites sur y sureste de los terrenos de la nueva colonia.

66 ERCC, fol. 14 r.-15 v.

67 Según los Estados Generales (1755), 2.313 fanegas de las tierras de sembradura, 36,61\% del total, se dedicaban a las rozas y necesitaban un descanso de 15 años. Vid. OJEDA RIVERA, J. F.: Organización ..., op. cit. p. 34. 
se eche a la tierra una cama de estiercol'. Por esta causa de la esterilidad del terreno, los regidores del ayuntamiento de Almonte ven serias dificultades en que el terreno elegido para la nueva población pueda mantener a sus colonos. En el orden a los inconvenientes que puedan ocasionar la instalación de la nueva colonia a los vecinos de Almonte son menos pesimistas que los peritos y hablan de "algun corto perjuicio" al reducirse la extensión de los pastos comunales. En lo que no tienen dudas es que el terreno demarcado; aunque baldío de la villa de Almonte, ${ }^{68}$ es del "dominio solariego, territorial y jurisdiccional del mayorazgo" de la casa ducal de Medina Sidonia.

El 28 de septiembre de 1768, El Superintendente Pablo de Olavide recibe de manos de Fernando Pérez de Guzmán un extenso expediente con la relación y tasación de sus bienes vinculados efectuados por peritos y que pretende vender para financiar la nueva colonia agrícola, por un importe neto de 2.249.809 reales de vellón, más 150 cabezas de ganado vacuno y 230 de cerda para repartir entre los colonos. ${ }^{69}$

Una vez reunida toda la documentación e informes requeridos por el Fiscal del Consejo de Castilla, el Asistente de Sevilla, en 6 de octubre de 1768 evacua su informe al Consejo de Castilla sobre el proyecto presentado por Fernando Pérez de Guzmán, con un extenso, detallado y pormenorizado estudio de las condiciones exigidas por el poblador en su pliego de 10 de abril de 1768 y de los estudios previos que acordó el Consejo a propuesta de su Fiscal, donde incluía nuevas recomendaciones. ${ }^{70}$ Pablo de Olavide, tras realizar un resumen de sus actuaciones, inicia el dictamen expresando que le "parece mui util para el Estado" el establecimiento de una nueva población en un terreno que está "desierto y abandonado". La obra del pretendido canal no sólo servirá para ampliar la navegación por el Guadalquivir y extender el comercio hacia Sevilla, Cádiz y sus importantes puertos, sino que si se le añadiesen al canal unos diques adecuados para el completo desagüe de las marismas se podrían aprovechar y poner en cultivo un "terreno inmenso". La pretendida inutilidad del terreno que manifiestan los peritos y ayuntamiento de Almonte y que excluye la posibilidad práctica de una nueva población no convence a Pablo de Olavide por la sospecha de que "generalmente miran con oposicion los antiguos colonos á los que tratan de establecer de nuevo". El Intendente tampoco aprecia el perjuicio que se ocasionaría a la ganadería de Almonte e Hinojos la reducción de sus pastos; ni el estorbo que significaría la existencia del dominio solariego que pretende el señorío de la casa de Medina Sidonia sobre aquel paraje, pues ante terrenos incultos, como se dicen que son, corresponde

68 Sin embargo y para dar cumplimiento al Interrogatorio enviado por la Real Junta de Baldíos y Arbitrios (Real Cédula de 21/04/1739), el ayuntamiento de Almonte considera Bienes de Propios, entre otros, las dehesas Boyal, Parrilla, Chaparral, Turmal, Cañada, Rocina, Rincón, Cańuelo y la Dehesilla de Los Hombres. AMA, leg. 837. Inclusión que se hace quizás por temor a su posible venta por la Corona, como ocurrió en otros términos municipales de Espańa, pues según los documentos más antiguos que se conservan en el Archivo Municipal de Almonte, las dehesas de Rincón y Cañuelo eran baldíos; vid Acta Capitular de 28/09/1608, leg. 3, fol. 56 v.

69 ERRC, fol. 16-32 v. La mayoría son bienes raíces: tierras de pan sembrar, olivares, pinares, cortijos, molinos y casas, localizados en los términos de Llerena, Berlanga, Bienvenida, Ayllones, Llera, Villagarcía, Pina, Cubas, Griñón, Trebujena, Sanlúcar de Barrameda y en la ciudad de Sevilla.

70 ERRC, fol. 33 r. $-40 \mathrm{v}$. 
a la Corona el superior derecho de darle otra utilidad más provechosa; igualmente manifiesta que las tercias reales que se generen de la actividad productiva de los colonos tampoco repercutirían a la casa de Medina Sidonia, ya que por su cualidad de novales, pertenecen al Real Patrimonio o a quien se subrogase en la erección de la nueva población, como establecen los capítulos 19 y 58 de la Instrucción y Fuero de Población de Sierra Morena.

Rechazados por Olavide estos principales obstáculos que representarían los posibles perjuicios a terceros, considera inmediatamente que "no ay reparo en que se conceda permiso para poblar las 3.500 fanegas de tierra", donde cabrían 70 vecinos en parcelas de 50 fanegas cada uno, como se establecía en el capítulo 8 del Fuero, y recibiendo los colonos los mismos auxilios que la Real Hacienda tiene previsto para los de Sierra Morena, es decir, casa, utensilios, semillas y ganado de labor, detalles que indica don Fernando en la condición primera de su proyecto poblador. A la consideración de que estas "familias" de colonos que pretende Fernando Pérez de Guzmán de sacarlas de donde pueda, Olavide previene y aconseja:

“(...) que no ha de poder valerse de los vecinos utiles contribuyentes que estan arraigados en los pueblos, por que esto no seria aumentar sino trasladar de un lugar á otro la población. Debe pues obligarse á hazer la que propone con aquellos vecinos sobrantes que por carecer de tierras propias y de caudal con que arrendar y cultivar las agenas estan reducidos al miserable estado de pobres jornaleros fomentandolos por los medios que previene el fuero de poblacion de Sierra Morena para que asi se convierta en labradores bien estantes capazes de promover la agricultura”.

Estos colonos deben obtener, continúa el Intendente, las mismas exenciones fiscales temporales establecidas en Sierra Morena, así como regirse por las leyes redactadas en la Instrucción, como recomienda el capítulo 53 del Fuero. ${ }^{71}$

Sobre la condición exigida por el poblador de obtener privilegio para el cerramiento o acotamiento de las tierras, el Intendente no sólo no tiene inconveniente, sino que considera que con ello se aumentaría el valor del terreno y facilitaría a los colonos "el medio de multiplicar las producciones que no podrian conseguir si fuesen abiertas". Tampoco pone obstáculos a que el Consejo le de la posesión del terreno elegido para la nueva población, como uno de los medios principales que hay que facilitar al nuevo poblador; así como la cesión del derecho en el cobro de los diezmos que se produzcan en el futuro, porque "es justo pues obligandose á poblar de su quenta aquel sitio debe remunerarsele su desembolso y trabajo", tal como se estipula además en el capítulo 58 del Fuero. En este punto, previene Pablo de Olavide que sería conveniente fijar un plazo para la conclusión de esta nueva población, como en parte estipula el capítulo 54.

71 "Esta Instrucción se ha de colocar tambien á la cabeza de los libros de repartimiento, para que en todo tiempo conste de ella, y la miren los nuevos establecimientos como un fuero invariable de población, y una regla para las que en adelante se vayan estableciendo de nuevo, á exemplo de las actuales". Novísima Recopilación, Libro VII, Título XXII, Ley III, cap. 53. 
La misma disposición favorable tiene el Asistente de Sevilla a que se concedan al proyectista Fernando Pérez de Guzmán los dos caños desaguaderos que cita en su solicitud para la construcción de un canal y que "este se declare ser suio y de sus herederos", con toda propiedad por el elevado desembolso que ha de realizar y por su importancia para el interés general; pero advierte que deben reglarse las utilidades de aquel para no perjudicar al comercio. Sobre la condición sexta que propone Fernando Pérez de Guzmán referente a obtener licencia real para cerrar y enajenar sus bienes vinculados o amayorazgados, Olavide considera “indispensable" que el Real Consejo apruebe esta exigencia para facilitar su enajenación y venta, pero "con las precauciones competentes que aseguren su imbercion" en el nuevo establecimiento agrícola. En este asunto, Olavide amplia sus argumentos porque ve además otros nuevos beneficios ańadidos:

"Estas enajenaciones produciran de que comprados los bienes vinculados por personas industriosas los mejoren y hagan mas utiles, á cuio intento conducirá mucho el privilegio de cerramiento que en mi dictamen $^{72}$ se dezia extender á todas las tierras, unico medio de que produzcan todo lo posible en que consiste la verdadera utilidad del propietario y del Estado. Y el dicho Don Fernando actual poseedor de estas tierras vinculadas, convertira su producto en un nuevo establecimiento que favorece á la agricultura, multiplica la poblacion y mejorara si se consigue su condicion y la de su familia”.

En cuanto a obtener Fernando Pérez de Guzmán prioridad en el cobro del censo de 6.300 ducados de vellón que le debe el ayuntamiento de Sevilla, igualmente Olavide no ve inconveniente pues será también invertido en el proyecto. El dictamen finaliza al informar sobre la séptima y última condición del pliego, en donde se aconseja que el grado de coronel y el sueldo correspondiente que solicita el proyectista como premio a su empresa, se debe cumplir siempre que finalice la nueva población, y sobre todo, cuando concluya el canal navegable comprendido en el proyecto.

Como puede observarse, el Asistente acepta todas las condiciones exigidas por el nuevo poblador ya que en su mayoría coinciden y se ajustan en lo reglado para las nuevas poblaciones que, precisamente en aquel año de 1768, empezaban a formarse en Sierra Morena. ${ }^{73}$ En otros capítulos del proyecto repoblador de Fernando Pérez de Guzmán se establece una coincidencia que podríamos llamar ideológica con las propias ideas de Pablo de Olavide sobre los problemas y soluciones para la agricultura, especialmente la andaluza, como es el caso de poblar algún terreno "desierto y abandonado", de que los terrenos sean acotados y cerrados al aprovechamiento ganadero del común de vecinos, de preferir campesinos sin tierras para las nuevas roturaciones,

72 Se refiere Olavide al Informe sobre la Ley Agraria que emitió al Consejo de Castilla.

73 Los colonos llegan a lo largo de la segunda quincena de septiembre de 1767 y empiezan a desbrozar y construir las casas en los primeros poblados de La Peńuela, Guarromán y Santa Elena. En el año 1769 sólo se habían sembrado 9.300 fanegas en las primeras 358 suertes repartidas; vid. RUÍZ GONZÁLEZ, J. E.: Estudio de la repoblación y colonización de Sierra Morena. Jaén, 1986, p. 89 . En 1770 aumentó a 14.396 fanegas de sembradura, según carta de Manuel Lanes Duval (La Peńuela, 17 de enero de 1770) a la duquesa de Medina Sidonia, AFCMS, leg. 2.376. 
o de estar muy a favor en la puesta en venta de tierras vinculadas o amayorazgadas; cuestiones que definen una parte de los tantísimos "males que aquejan al campo andaluz" según Pablo de Olavide. Y esto se comprueba fácilmente en el dictamen que el propio Olavide emitió al Consejo de Castilla, al ser requerido por éste para formar el expediente de la futura Ley Agraria ${ }^{74}$; informe-proyecto que, por su exhaustivo análisis de la realidad socioeconómica de la agricultura andaluza, sus problemas y propuestas de solución que incluye, ha sido considerado por un especialista en la materia como el primer proyecto legislativo para una reforma agraria en Andalucía. ${ }^{75}$

En definitiva, el proyecto de una nueva colonia agrícola, de un nueva población en un desierto que pusiese en explotación unos terrenos abandonados e incultos por manos de pobres jornaleros, suponía, para Olavide otra ocasión de puesta en práctica de sus ideales sociales -labradores con tierras y útiles a la Nación-- y agraristas -que se labre mejor, más y cuanto se pueda labrar-- que acababa de esbozar y proponer al Consejo de Castilla, como informe previo a la proyectada Ley Agraria; germen legislativo de un Gobierno ilustrado empeńado en resolver los acuciantes problemas que aquejaban a la agricultura espańola en su conjunto para alcanzar la "felicidad pública"; la apuesta gubernativa, en fin, por una España agraria y bien poblada. ${ }^{76}$

\section{Paralización de Guzmanópolis y la Nueva Población del Rocío.}

Tras algunas injustificadas, aunque no inexplicables, paralizaciones judiciales y extrajudiciales del expediente de Fernando Pérez de Guzmán en el Real Consejo de Castilla, éste vuelve a abrirse pero ahora en el nuevo ministerio que se haría cargo de las nuevas poblaciones, el Real Consejo de Gracia y Justicia. El 22 de enero de 1777, este Consejo acuerda que el expediente pase a informe del Procurador del Reino quién un mes después da el visto bueno al proyecto Guzmanópolis:

"El pensamiento es utilisimo y digno de admitirse por las ventajas que proporciona á el Estado y logra la Causa Común con la formacion de una nueva poblacion en que dar establecimiento a muchos vecinos pobres que pueden acomodarse en el distrito á que a reducido el expresado Don Fernando (...). No solo proporciona este establecimiento el beneficio y utilidad que resulta de la nueba poblacion, verificada que sea, sino es que sy exemplar puede servir de estimulo y aliciente á que otros vasallos poderosos ó que tengan suficientes medios para ello

$74 \mathrm{El}$ informe se solicita al Asistente de Sevilla en 18 de febrero de 1768 y lo cumplimenta en 20 de marzo de ese mismo año. El Consejo solicitó también informes a los Intendentes de Córdoba, Jaén, Granada, Ciudad Real y Extremadura; vid. Informes en el Expediente de la Ley Agraria. Madrid, 1990. Incluso a otras autoridades en particular, como al ministro decano de la Real Audiencia de Sevilla, Francisco de Bruna; sobre el Informe de éste, vid. ANES, G.: "Pensamiento ilustrado sobre problemas agrarios en Andalucía: la aportación de Francisco Bruna y Ahumada"; en Andalucía en el pensamiento económico; GUMERSIDO RUÍZ, (Coord.), Málaga, 1987, pp. 89-96.

75 MERCHÁN, A.: La reforma agraria ..., op. cit., Sevilla, 1997.

76 ROBLEDO HERNÁNDEZ, R.: Economistas y reformadores españoles: la cuestión agraria (1760-1935). Madrid, 1993, p. 17. 
se dediquen á emprender semejantes establecimientos en el espaciado terreno que ocupan las marismas á el presente inutilizadas por la inundacion; si se logra el desaguarlas con el canal que proyecta ejecutar para navegacion y comercio, de que igualmente conseguiran los pueblos inmediatos considerables beneficios y utilidades, en el pronto despacho de sus frutos y mas comodidad de precios en los abastos (...) le parece á el Procurador General que si V. A. tuviese á vien concederle el permiso que pretende, con las precauciones que juzgue mas convenientes, y llegare a verificarse el establecimiento, ocasionaria sin duda grandes utilidades beneficios y ventajas á la causa Común y al Estado; las que serian mucho mayores si efectuado el canal se lograse el desaguar las marismas pues aun quando en su terreno no se efectuasen á su imitacion otras poblaciones, se lograria el aprovechamiento de sus pastos y que los pueblos inmediatos se libertasen de las epidemias (...) y asi no alla inconveniente en que se conceda á el expresado Don Fernando el terreno que solicita (...)" ${ }^{77}$

De nuevo, otra parálisis judicial. Ahora la dilación del expediente se debe al Consejo que no retoma el asunto de la nueva población hasta transcurrido seis meses en su reunión de gobierno del 22 de septiembre de 1777, en que acuerda que antes de pasar el expediente a consulta del rey debe producirse una aceptación por escrito de Fernando Pérez de Guzmán de todos los capítulos del proyecto así como de las adiciones efectuadas por el Regente de Sevilla y las propuestas por el Fiscal en su último informe, pero además el Consejo propone una última: Fernando Pérez de Guzmán debe construir y adornar una iglesia parroquial en la nueva colonia agrícola asegurando la dotación para el cura correspondiente; siendo este patronato perpetuo de Fernando Pérez de Guzmán y sus sucesores; y todo para que los nuevos colonos tengan su "pasto Espiritual'. La aceptación por parte de Fernando Pérez de Guzmán se produce sólo tres después, pero de nada serviría ante la presión de la Casa de Medina Sidonia.

El 4 de noviembre de 1777 y por "vía reservada" el ministro de Gracia y Justicia, Manuel de Roda, por orden expresa de Carlos III, remite al Gobernador del Consejo de Castilla una solicitud que el duque de Medina Sidonia había presentado al rey, para que dicho Consejo "consulte en su vista lo que se le ofreciere y pareciere". En la propia misiva de Roda se resume el contenido de la solicitud:

"En el adjunto memorial solicita el Duque de Medina Sidonia, que desestimando las proposiciones y pretension introducida por Don Fernando Perez de Guzman sobre que se le diese facultad para poblar dos leguas de tierra en el sitio que llaman del Rocio, termino de la villa de Almonte, se mande dejarle libre al mismo Duque, de cuyos Mayorazgos es propio aquel termino, el uso y facultad de poder poblar y repartir 
por si, o por medio de personas de su satisfaccion con quienes se convenga, asi aquel como los demas terminos desiertos de sus Estados, concediendole el derecho de percibir los diezmos novales de las tierras que se rompan y cultiven, y el privilegio de poder eximir de toda carga y gabela á los nuevos pobladores por algun tiempo determinado, á manera de lo que se observo en las nuevas poblaciones de Sierra Morena. Y de orden del Rey lo remito a V. Y." ${ }^{78}$

Esta acción de última hora del duque de Medina Sidonia, Pedro de Alcántara, podría parecer a simple vista sorpresiva pero no tenía otras opciones después de haber utilizado su alta influencia en frenar todo lo posible los procedimientos judiciales del expediente de la nueva población Guzmanópolis en el Real Consejo; sino solo esta opción de convertirse el mismo en "poblador" de aquellos terrenos cuando el Consejo acordó finalmente finiquitar el expediente ante el rey a favor de Fernando Pérez de Guzmán, pasándolo a su consulta y aprobación definitiva.

El duque Pedro muere a finales de 1779. El expediente vuelve a paralizarse casi diez años y lo retoma su sucesor, José Álvarez de Toledo, duque de Medina Sidonia y Alba. Pero este rechaza de antemano el antiguo proyecto de Fernando Pérez de Guzmán deseando encontrar "un sitio mas sano, mas util y á proposito". En este sentido, envía en 28 de enero de 1788 una extensa carta-orden al tesorero y administrador del Condado de Niebla, Roque Díaz Ángel del Castillo, nombrándole director de la "empresa" y que en unión de "persona de entera confianza asi en el terreno como en la actividad" deberán de estudiar y cumplir con una serie de objetivos. Estos serían los siguientes.

Los terrenos deberán ser preferidos cerca de Marismilla, palacio de Dońa Ana o ermita del Rocío, para que sirva por ahora de parroquia a los nuevos feligreses; si la ermita no fuese propiedad de la casa ducal deberá elegirse el oratorio del Palacio. La nueva población se situará cerca de las suertes de tierras que se han de repartir que deberán medirse juntamente con la tierra destinada a dehesa boyal y ejido, no tomando como referencia las 3.500 fanegas del proyecto de Fernando Pérez de Guzmán, sino lo necesario para los 70 colonos con sus 50 fanegas dotacionales, más algunos terrenos para ejido y dehesa boyal, ya que sobra terrenos en sus dominios, y también terrenos para senara o peujar concejil y así cubrir los gastos del común; todo este terreno quedará cerrado y acotado. Prosigue el Duque que "convendria dar al nuevo establecimiento toda la extension compatible con la constitucion actual de dichos pueblos comarcanos al territorio, para proporcionar todos los auxilios posibles á los pobladores y excitarlos á que concurran á establecerse, y con esta misma idea se podra tambien destinar algun pedazo de terreno apto para plantio de arboles ó viñas que devera distribuirse con igualdad'; las tierras que tengan la misma calidad deben estar a la misma distancia de

78 ERCC, fol. 255 r.-256 r. 
las casas; debe repartirse con igualdad algún terreno para regadío. Estas casas no han de estar juntas a imitación de los pueblos, sino inmediatas a las haciendas asignadas, pero en todo caso - precisa el Duque-- cuando no lo permitan las suertes se podrá construir dos, tres o cuatro casas juntas que también es conveniente pues se auxilian unas a otras y los costos de construcción son más económicos. La dehesa boyal deberá estar próxima a todos los colonos y se cuidara de dejar los caminos y pasos necesarios entre las suertes; se deslindará cada suerte y estará suficientemente separadas para que cada uno aproveche privativamente sus cultivos por sus ganados, dando anchura a estos linderos para siembra de árboles y al mismo tiempo sirvan de veredas o caminos para los ganados; igualmente se procederá con la dehesa boyal, ejido y senara. Será imprescindible deslindar todo el término asignado a la población, tomando un mapa de todo con la mayor exactitud, distinción y claridad; “(...) la empresa es ardua y vasta -reconoce el Duque- por lo que he decidido proponerte por ahora solo en el primer paso que debe darse (...) me des mensualmente cuenta de lo que vayas delantando para hacerlo presente al Consejo (...) llevando una cuenta separada de los gastos que se ofrecieren". ${ }^{79}$

Puede apreciarse con toda exactitud que este modelo de nueva población sigue fielmente el diseńado para las de Sierra Morena. Y con respecto al anterior propuesto por Fernando Pérez de Guzmán presenta ciertas diferencias y cualidades. No se fija ninguna extensión de terreno, sino el necesario para asentar setenta colonos siguiendo el modelo de Sierra Morena con sus comunales para que sus habitantes dispongan de todas las comodidades productivas: parcelas de 50 fanegas, terrenos para ejido, dehesa boyal, senara concejil, los suficientes para vińas y árboles frutales y para huertas; todos los terrenos particulares como comunales serán perfectamente deslindados, acotados y cerrados y se abrirán los pasos, veredas y caminos necesarios. La construcción de canales y la desecación de la marisma no se contemplan.

Siguiendo las instrucciones del Duque, Roque Díaz se desplaza a la villa de Almonte en compañía del maestro arquitecto y agrimensor Francisco Díaz Pinto ${ }^{80}$ y de Alonso de Orihuela, labrador que también ejerce los oficios de ladrillero, canalajero y calero, ambos vecinos de La Palma -hoy del Condado en la actual provincia de Huelva--. En Almonte, el día 21 de febrero de 1788, se reúnen con su corregidor, el licenciado Lorenzo Fernández Vélez, quién inicia el expediente de reconocimiento de los terrenos, haciendo constar en primer término que las tierras inmediatas al coto de Dońa Ana no son aptas para labrantíos, por lo que recomienda el nombramiento de peritos inteligentes para elegir los terrenos más adecuados para la nueva población. Se nombran a los palmerinos citados, a los vecinos de Almonte Lucas Lozano y Juan Miguel Roldán, y al tesorero del cabildo almonteńo, que todos se dan por notificados, juran y aceptan el nombramiento, quedando para iniciar el peritaje el primero de marzo.

79 ERCC(Tomo II), fol. 41 r.-44 r.

80 AFCMS, leg. 1731. Es este documento aparece como maestro alarife. Efectivamente en Huelva, como "maestro alarife principal", ejecuta la nueva torre de la iglesia de San Pedro (1774), la Iglesia del convento de La Merced (1785) y la restauración de la iglesia de la Concepción (1785). Vid.: FALCÓN MÁRQUEZ, T.: Documentos para el estudio de la arquitectura onubense. Huelva, 1977, pp. 18, 30, 172, 179,184 y 188 . 
En ese día recorren los terrenos demarcados por Fernando Pérez de Guzmán en el entorno del Rocío y que miden en 25.262 fanegas (15.020,7 hectáreas), ${ }^{81}$ no encontrando terrenos para semillas ni plantíos de árboles y viñas ni materiales para la construcción de casas y molinos, siendo el sitio insalubre para habitarlo y sólo aprovechable para pastos de ganados, en la misma consideración -afirman- que lo vieron anteriores prácticos y peritos. Luego pasan al coto de Dońa Ana que recorren en toda su extensión, midiéndolo en unas 146.522 fanegas (87.121,9 hectáreas), ${ }^{82}$ donde tampoco hallan terrenos aptos para ningún tipo de labor y plantíos, haciendo constar que los plantones de vińas existentes al sitio de Las Gabarras en la dehesa de Marismillas son muy endebles; igualmente no son aptos para fabricación de ladrillos y molinos. ${ }^{83}$

Con fecha 13 de marzo, Roque Díaz envía al Duque el informe de los peritos y la certificación del agrimensor de las mediciones efectuadas y de las calidades de los terrenos del Rocío y coto de Dońa Ana; el Duque lo remite al Consejo de Castilla el 16 de junio. ${ }^{84}$ Indica Roque al Duque que el presupuesto para la construcción de 70 casas, iglesia, casas capitulares, cárcel y posito es de dos millones y medio de reales. ${ }^{85}$ La carta de remisión es un extenso informe de la opinión personal de este administrador seńalando su total conformidad con el peritaje efectuado y una especie de alegato contra todos los intentos de la Casa de poner en cultivo el coto de Dońa Ana donde se ha fracasado y gastado enormes caudales, incluyendo una ácida crítica y desautorizando igualmente el proyecto de Fernando Pérez de Guzmán. Finalmente, recomienda y propone al Duque "experimentar con varios colonos, seis ú ocho, auxiliados convenientemente, eligiendo ellos mismos las cinquenta fanegas en cualquier sitio, y viviendo en chozas, y asi ver los efectos de la fertilidad ó inutilidad del suelo". ${ }^{86}$

El Duque está conforme con esta propuesta de su administrador y así se lo comunica en carta fechada en Madrid en 19 de junio de 1788:

“(...) y la ninguna esperanza de que produzca fruto alguno este intento, sin embargo de lo qual y demas poderosas razones de su crecido costo, estando adoptada por el Consejo esta idea y conformandome

81 Vid. Mapa no 2 del Apéndice Documental.

82 Vid. Mapa no 3 del Apéndice Documental.

83 ERCC(II), fol. 45 r.-53 v. Estuvieron 10 días en las mediciones y peritajes, pernoctando en la casa de campo de José Mecoleta, vecino de Almonte, con un costo total de 5.034 reales. Testimonio de gastos de la Nueva Población, Almonte, 10 de septiembre de 1794. AFCMS, leg. 1.962.

84 ERCC(II), fol. 60 r.-61 r. Cuando la información provenga del expediente del Real Consejo de Castilla, obviaremos comentar que es el Duque quién se la remite al Consejo, pues tiene obligación de ello cada quince días, a propuesta de Fernando Pérez de Guzmán y aprobada por el Consejo en su resolución de 9 de noviembre de 1787, ERCC, fol. 35 r.

85 La nueva población de El Algar para 90 vecinos con los mismos edificios civiles se presupuestó en 832.050 reales. Vid.: GONZÁLEZ BELTRÁN, J. M.: "La población señorial del Algar (Cádiz) en el contexto de las nuevas poblaciones", en AVILÉS, M. y SENA, G. (Ed.): Nuevas poblaciones en la España Moderna, Córdoba, 1991, p. 446.

86 ERCC(II), fol. 54 r. -59 r. 
con ella no se puede abandonar sin que preceda una fisica demostracion de la insinuada imposibilidad, á cuyo efecto y tentar todos los caminos que pueda conducirnos al fin deseado, es preciso adoptar el ultimo medio que propones de establecer seis ú ocho colonos (...) con lo qual se hara un ensayo patente de la prosperidad ó inutilidad que podra esperarse de dicha poblacion (...) para proceder á plantificar esta idea con la posible economia (...)" ${ }^{87}$

El 13 de febrero de 1789 se instalan las primeras familias a la Nueva Población del Rocío, se construyen chozas y casas, llegan nuevos contingentes de colonos en 1794 y la nueva colonia agrícola permanece activa hasta enero de 1810 , que la abandonan ante la llegada de los ejércitos napoleónicos a la villa de Almonte. Durante esos ańos, la colonia sufrió los rechazos de un entorno hostil, social y político, pero llegó a transformar en agrícola un extenso territorio y su paisaje hasta ahora secularmente destinado a la ganadería extensiva. Sobre estos mismos terrenos, siglo y medio después, se desarrollaría la nueva agricultura intensiva de regadío; aquellos colonos fueron los pioneros.

\section{Conclusiones.}

La colonia Guzmanópolis se enmarca dentro del contexto de las nuevas poblaciones y repoblaciones promovidos por el gabinete ilustrado de Carlos III, proyectados o ejecutados por la iniciativa privada de ciudadanos que acudieron a los incentivos emanados del Fuero de Sierra Morena y del Fuero Alfonsino. La envergadura del proyecto de Fernando Pérez de Guzmán sobrepasaba las novedades ilustradas de crear nuevas poblaciones sobre zonas baldías para aumento general de la agricultura y las manufacturas; erigir dos nuevos canales en la desembocadura del Guadalquivir -obras de ingeniería civil costosísimas - para desarrollar el comercio de productos onubenses, sevillanos y gaditanos se enmarcaba también dentro de las propuestas de muchos teóricos-economistas para el despegue y desarrollo general de la maltrecha y anquilosada riqueza nacional. Meses antes que se presentara Guzmanópolis ante el Consejo de Castilla, Carlos Sabater y su compañía de inversores, presentaban un proyecto similar en la desembocadura del Ebro.

Guzmanópolis no llegó a realizarse a pesar del tesón de Fernando Pérez de Guzmán, tras 19 años de trámites en los Reales Consejos. Avatares de la alta política de la época, la enorme presión de las casas de Medina Sidonia y Alba sobre los Reales Consejos y el propio monarca e incluso reticencias de los propios familiares de Fernando Pérez, impidieron la realización de tan novedoso proyecto privado muy acorde a las ideas ilustradas. Este proyecto sufriría también, como otros muchos de la época, el freno de las reformas agrarias y poblacionistas de Carlos III tras los sucesos de 1769 acaecidos en las nuevas poblaciones de Sierra Morena y Andalucía, que romperían la cohesión del mejor gabinete reformista: Aranda-Campomanes-Múzquíz. A pesar de 
todas estas resistencias ante la erección de una nueva población en los aledaños del antiguo Coto de Doñana, la persistencia de Fernando Pérez de Guzmán ante el Real Consejo de Gracia y Justicia consiguió de éste su aprobación al proyecto y acuerdo de 16 de febrero de 1784 para que pasase a consulta definitiva del rey. Al duque de Alba, heredero en estas fechas del estado de Medina Sidonia, no le queda otra salida que ejecutar esa nueva colonia, que se denominará "Nueva Población del Rocío". ${ }^{88}$ Proyecto de menor envergadura que el diseñado por Fernando Pérez de Guzmán, llegó a realizarse y perduró hasta enero de 1810; esta nueva colonia es objeto actual de nuestros estudios.

Esta investigación que ofrecemos pretende resaltar que, además de mostrar un proyecto ilustrado concreto, las ideas reformistas del Siglo de las Luces llegaron a estas tierras confines de la Andalucía onubense y que algunos de sus ciudadanos abrazaron aquellas ideas y trataron de ponerlas en valor mediante la realización de proyectos concretos. Clarísimo queda que esta humilde aportación evidencia también las carencias historiográficas que aún sufre el siglo XVIII en las tierras de Huelva, especialmente de aquellos ańos ilustrados, cuyas ideas sobrepasarían la centuria del Setecientos. 


\section{APÉNDICE DOCUMENTAL.}

\section{Plano ${ }^{\circ}$ I.}

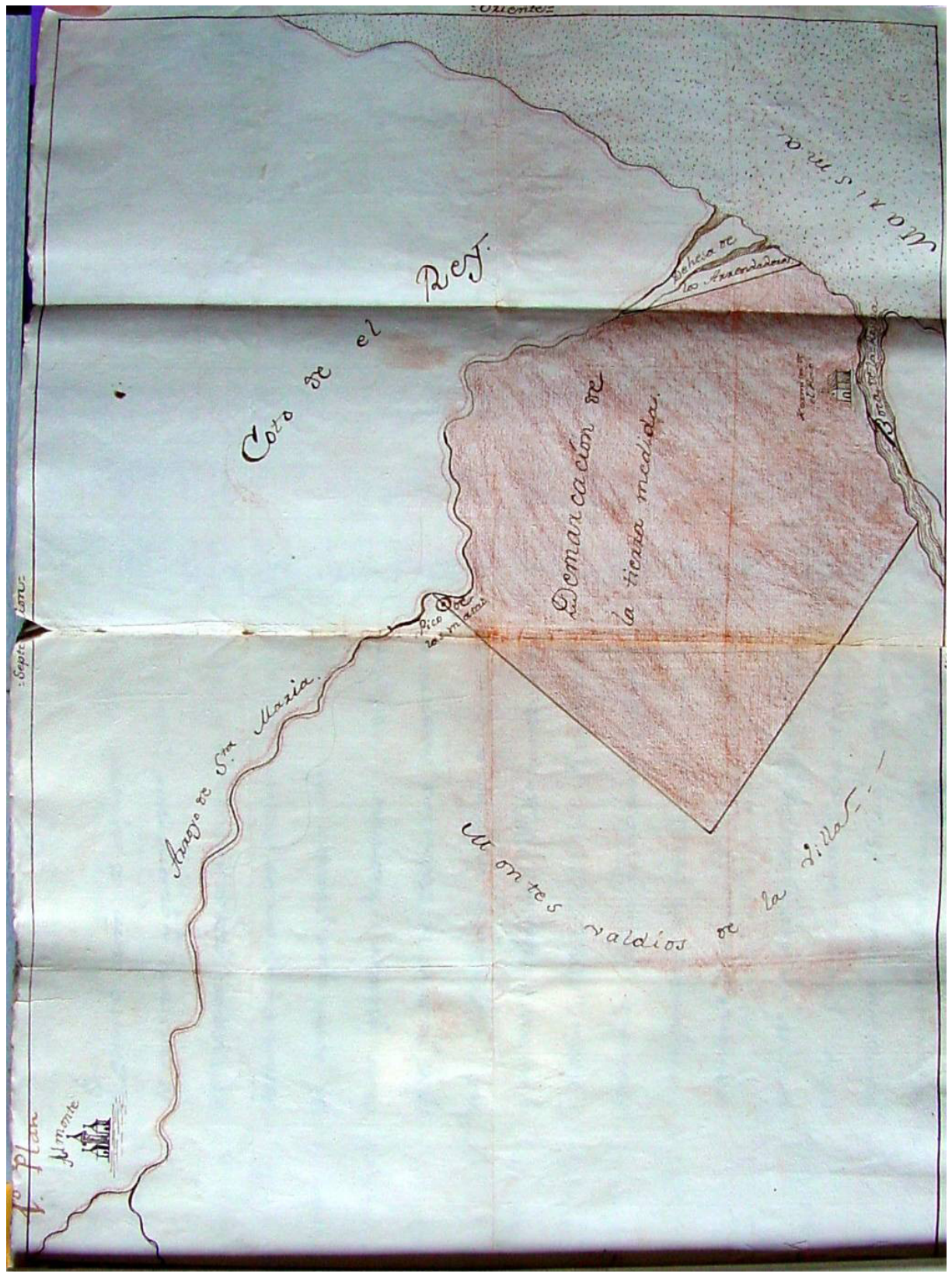




\section{Plano no 1.}

\section{Descripción:}

Sobre papel, tinta y lápiz. 41 x 30,5 centímetros. Posible fecha de realización entre junio y julio de 1768. Autor: Juan Baena (Agrimensor, vecino de la ciudad de Sevilla).

Textos:

$1^{\circ}$ Plan. Almonte [dibujo de iglesia]. Septentrion. Arroyo de Sta. Maria. Coto de el Rey. Pico de las Matas. Oriente. Demarcación de la tierra medida. Montes valdios de la villa. Dehesa de los Arrendadores. Hermita de Ntra. Sra. del Rocio [dibujo de ermita]. Boca de la Rosina. Marisma.

Signatura de archivo: AFCMS, leg. 708. 


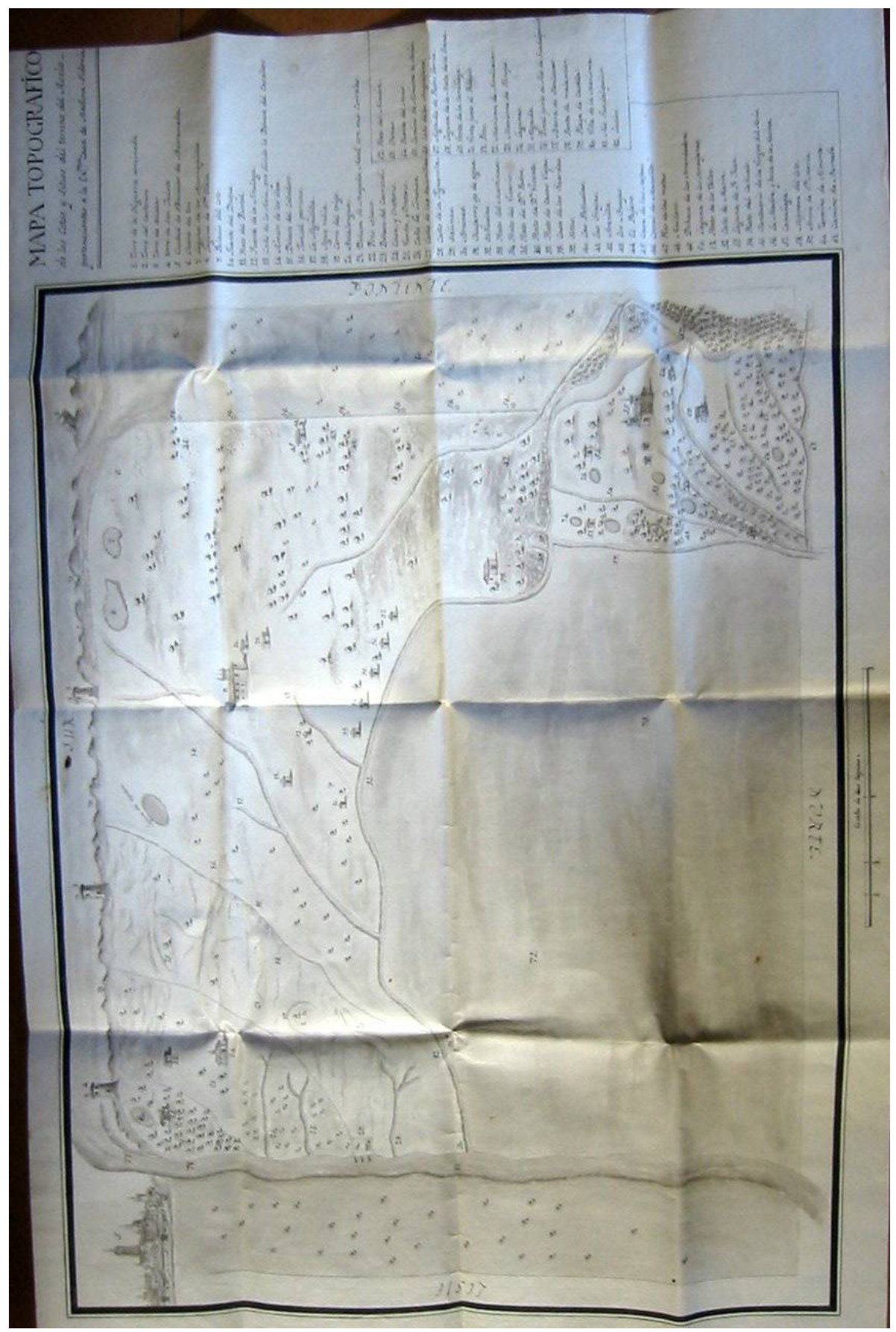




\section{Plano no 2. (Ampliación del no 3).}

Descriptores:

38: Casa de los Guardas

39. Sotos

40: Las Peńuelas

42: Arenilla

47: Pico de Las Matas

48: Ruidero

49: Dehesa de Los Arrendadores

50: Laguna de Los Arrayanes

51: Hato de Los Tellos

52: Caño Marin [En plano con el no 54]

53: Laguna de Fr. Juan

54: Hato del Cañuelo

55: Santuario de la Virgen del Rocio

56: La Madre y boca de la Rosina

57: Canaliega

58: Mojonera del Coto

59: Arroio de Sta. Maria

60: Termino de Almonte

61: Camino de Bernabé

62: Hato del Rincón

63: Chozas

64: Fuente del Rocio

65: Camino de Almonte al Rocio

66: Caño de Los Anguilleros

67: Algaida de Pedro Garcia

68: Laguna de la Mata de La Grana

69: Venta de La Canaliega

74: Lagunas 


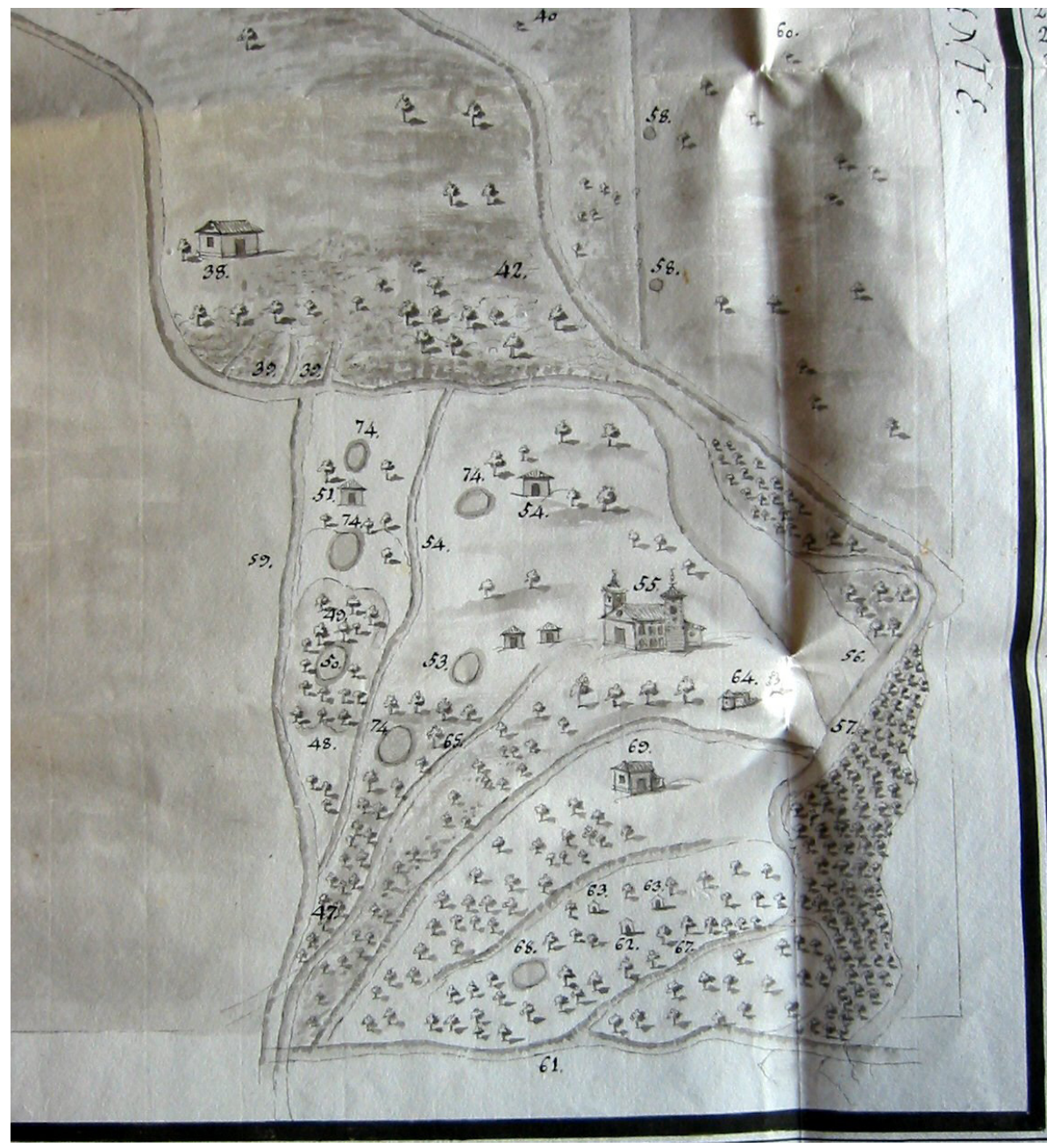




\section{Plano no 3.}

Descripción:

Sobre papel, tinta. 140 x 100 centímetros. Posible fecha de realización entre septiembre y octubre de 1789. Autor: Francisco Díaz Pinto (Agrimensor y Maestro Alarife, vecino de La Palma del Condado).

Texto:

"MAPA TOPOGRAFICO de los Cotos y Sitios del terreno del Rocio pertenecientes á la Exma. Casa de Medina Sidonia”.

Descriptores: 82 .

Signatura de archivo: AFCMS, legajo 1.962. 


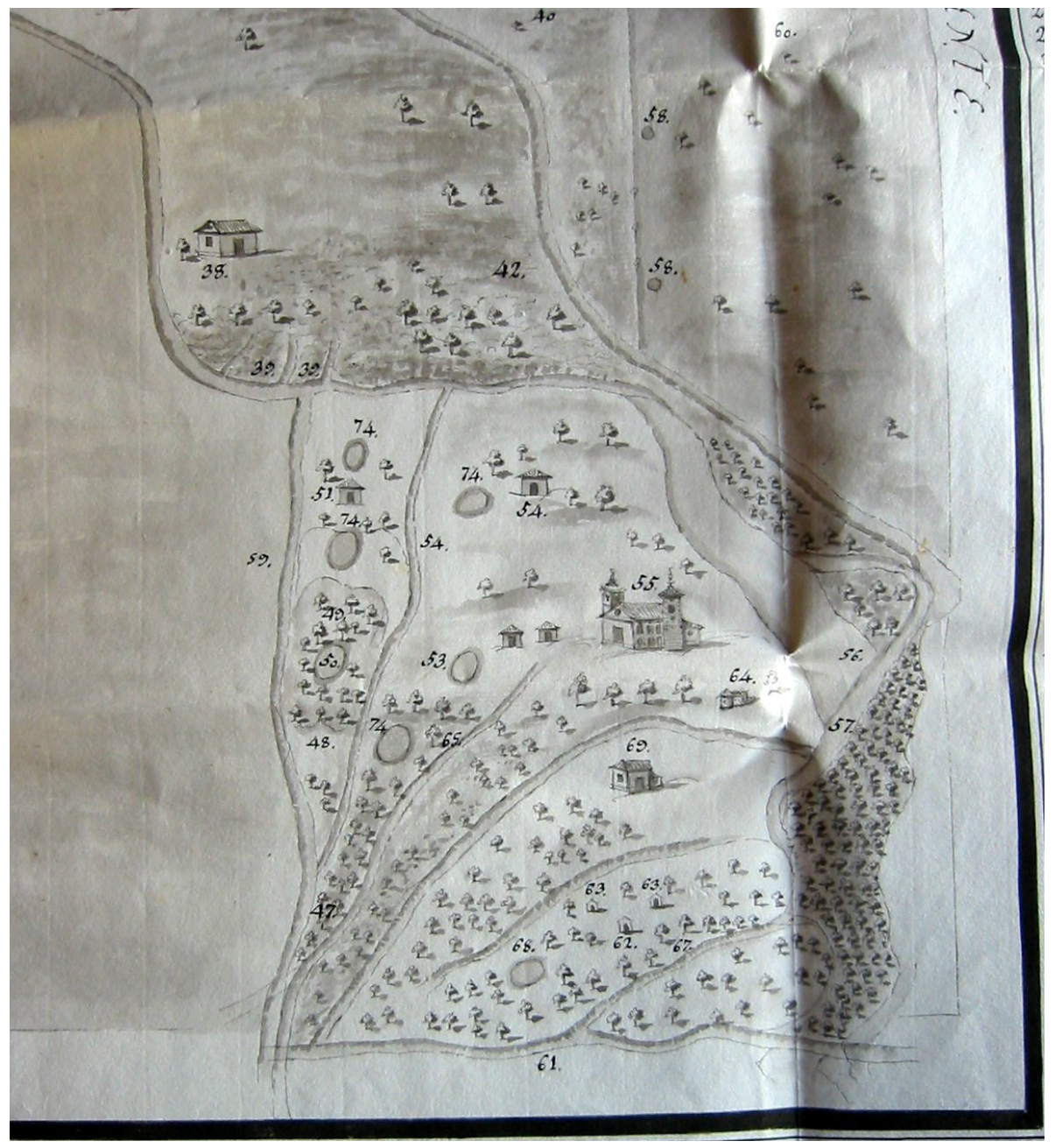




\section{BibLIOGRAFIA DE REFERENCIA}

AGUILAR PIÑAL, F.: La Sevilla de Olavide, 1768-1778. Sevilla, Ayuntamiento de Sevilla, 1995.

ALBEROLA ROMÁ, A. y GIMÉNEZ LÓPEZ, E.: "Antecedentes colonizadores en la España del siglo XVIII. Proyectos y realidades en las tierras de la antigua corona de Aragón”. Revista de Historia Económica. Año XV, Primavera-Verano 1997, no 2. pp. 269-293.

ANES, G.: Las crisis agrarias en la España Moderna. Madrid, 1974.

--Economía e ilustración en la España del siglo XVIII. Barcelona, 1981.

--"El pensamiento ilustrado sobre problemas agrarios en Andalucía: la aportación de

Francisco de Bruna y Ahumada", en Andalucía en el pensamiento económico. G.

Ruiz, (Ed.). Málaga, 1987, pp. 85-104.

--"Economía y sociedad”, en Actas del Congreso Internacional sobre Carlos III y la Ilustración. Ministerio de Cultura. Madrid, 1988, vol. II, p. 17.

--Informes en el Expediente de la Ley Agraria: (Andalucía y la Mancha): (1768). Edición y estudio por ... Madrid, 1990.

--Cultivos, cosechas y pastoreo en la España moderna. RAH., Madrid, 1999.

--“La economía española en el siglo XVIII”, en FUENTES QUINTANA E. (Dir.): Economía y economistas españoles. T. III, La Ilustración, Barcelona, 2000, pp. 91169.

ARRIQUIBAR, NICOLÁS DE.: Recreacion politica. Estudio preliminar y edición a cargo de Jesús Astigarraga y José Manuel Barrenechea. Instituto Vasco de Estadística, Bilbao, 1987.

AVILÉS FERNÁNDEZ, M.: "Historiografía sobre las $<$ Nuevas poblaciones $>$ de Carlos III", en Coloquio Internacional Carlos III y su siglo. Actas. Universidad Complutense, Madrid, 1990, tomo I, pp. 485-510.

BARRANTES MALDONADO, P.: Ilustraciones de la Casa de Niebla. RAH, Madrid, 1857, tomo IX.

CANO GARCÍA, M. I.: “La Nueva Población de Fuente Palmera (1768-1835)", en Actas II Coloquios Historia de Andalucía. Andalucia Moderna. Córdoba, 1983, T. I, pp. 239-264.

CAPEL MARGARITO, M.: "Pablo de Olavide, artífice de la Colonización de Sierra Morena y Andalucía y fundador de su capitalidad, Real Carolina (Proyecto de recuperación de su verdadera imagen)"; En AVILÉS FERNÁNDEZ, M. y SENA MEDINA, G. (Eds.): Las Nuevas Poblaciones" de Carlos III en Sierra Morena y Andalucía. Córdoba, 1985, pp. 339-361.

CARMONA RUIZ, M. A.: La ganadería en el Reino de Sevilla durante la Edad Media. Sevilla, Diputación Provincial, 1998.

CASTILLO SOTO, J.: "Las nuevas poblaciones de Sierra Morena bajo la superintendencia de don Pedro Pérez Valiente: oficios y colonos", en Espacio, Tiempo y Forma, Serie IV, H. a Moderna, t. V, 1992, pp. 283-296.

CASTRILLO DÍAZ, M. C.: Doñana nombre a nombre. Estudio de la toponimia del 
Parque Nacional de Doñana. Huelva, Diputación Provincial, 2000.

CASTRO, C. DE: Campomanes: Estado y Reformismo Ilustrado. Madrid, 1996.

DEFOURNEAUX, M.: Pablo de Olavide el Afrancesado. Sevilla, 1990.

DELGADO RIBAS, J. M.: "Floridablanca y el planteamiento de la política agraria de Carlos III", en Estructuras agrarias y reformismo ilustrado en la España del siglo XVIII. Actas del Seminario sobre Agricultura e Ilustración (Segovia, 1988), Madrid, 1989, pp. 639-662.

DOMÍNGUEZ ORTIZ, A.: El Régimen Señorial y el Reformismo Borbónico. (Discurso de entrada en la RAH), Madrid, 1974.

--Sociedad y Estado en el siglo XVIII español. Barcelona, 1976.

--Carlos III y la España de la Ilustración. Madrid, 1988.

FALCÓN MÁRQUEZ, T.: Documentos para el estudio de la arquitectura onubense. Huelva, Diputación Provincial, 1977.

FUNDACIÓN CASA MEDINA SIDONIA: Del exilio a la unión de las Casas. Los Guzmanes III (1665-1955). Col. "Cuadernos" no 5, [Sanlúcar de Barrameda], 2003.

GAMERO ROJAS, M.: "La nobleza titulada sevillana y su participación en el mercado de la tierra de 1700 a 1834"; en Coloquio Internacional Carlos III y su siglo. Actas. Universidad Complutense, Madrid, 1990, pp. 795-818.

--El mercado de la Tierra en Sevilla en el siglo XVIII. Sevilla. Universidad de Sevilla y Diputación Provincial, 1993.

GARCÍA TORRES, I. y LÓPEZ JIMÉNEZ, C.: "Écija y las nuevas poblaciones: conflictos e interés ante una nueva organización”, en Las Nuevas Poblaciones de España y América. Actas del V congreso Histórico sobre Nuevas Poblaciones. Sevilla, 1994, pp. 209-218.

GIMÉNEZ LÓPEZ, E.: "Fuero Alfonsino y Fuero de Población de Sierra Morena en los proyectos de colonización de la Corona de Aragón en la segunda mitad del siglo XVIII". Revista de Historia Moderna, no 12, Alicante, 1993, pp. 141-185.

GONZÁLEZ BELTRÁN, J. M.: "La población señorial del Algar (Cádiz) en el contexto de las nuevas poblaciones”, en AVILÉS, M. y SENA, G. (Eds.): Nuevas poblaciones en la España Moderna. Córdoba, 1991, pp. 433-454.

HERNÁNDEZ PERALES, A.: Historia de Prado del Rey. Cádiz, Diputación Provincial, 1968.

LADERO QUESADA, M. A.: Andalucía en el siglo XV. Estudios de Historia Política. CSIC., Madrid, 1973.

--“Los señoríos medievales onubenses", en Huelva en la Andalucía del siglo XV. Huelva, Diputación Provincial, 1986.

--Niebla, de Reino a Condado. Noticias del Algarbe andaluz en la Baja Edad Media. Huelva, Diputación Provincial, 1992.

--Los señores de Andalucía. Investigaciones sobre nobles y señorios en los siglos XIII a XV. Universidad de Cádiz, Cádiz, 1998.

--“Los señoríos medievales onubenses. Período de formación”, en CARRIAZO RUBIO, J. L. y MIURA ANDRADES, J. M. (Eds.): Huelva en la Edad Media 20 
años después. Universidad de Huelva, Huelva, 1998.

LARA RÓDENAS, M. J. DE: Un heterodoxo en la Huelva de la Ilustración: Miguel Ignacio Pérez Quintero. Huelva, Diputación Provincial, 1995.

--La Ilustración en las sacristias. El Vicario de Huelva y las respuestas a Tomás López.

Huelva, Junta de Andalucía, 1998.

--José Isidoro Morales, un matemático en la Corte de Carlos IV. Universidad de Huelva,

Huelva, 2001.

LOBO MANZANO, L.: Los usos del suelo en el área de Sevilla: Dos Hermanas, siglos

XVIII-XX. Tesis doctoral inédita, ejemplar mecanografiado, Sevilla, 1998.

LÓPEZ RUBIO, J. F.: "Algunas notas a los pleitos entre Villamartín y Prado del Rey

(1769-1886)", en AVILÉS FERNÁNDEZ, M. y SENA MEDINA, G. (Eds.):

Las "Nuevas Poblaciones" de Carlos III en Sierra Morena y Andalucía. Córdoba, 1985, pp. 303-310.

LÓPEZ SEBASTIÁN, J.: Reforma agraria en España (Sierra Morena en el siglo XVIII). Murcia, 1968.

LLOMBART ROSA, V.: “Álbum”, en FUENTES QUINTANA, E. (Ed.): Economía y economistas españoles. T. III, La Ilustración, Barcelona, 2000, pp. III-XXXII.

LLUCH, E. y ARGEMÍ, LL., Agronomía y fisiocracia en España (1750-1820). Valencia, 1985.

MERCHÁN, A.: La reforma agraria en Andalucía: el primer proyecto legislativo: (Pablo de Olavide, Sevilla, 1768). Universidad de Sevilla, Sevilla, 1997.

MORÁN MARTÍN, R.: "Plan de Repoblación en la segunda mitad del siglo XVIII y primera del siglo XIX”, en AVILÉS, M. y SENA, G. (Eds.): Carlos III y las Nuevas Poblaciones. Actas del II Congreso Histórico, Córdoba, 1988, t. I, pp. 243-270.

MORENO ALONSO, M.: "Historiografía de Huelva Ilustrada”, en JAVIER PÉREZ-EMBID y otros: Historia e historiadores sobre Huelva (Siglos XVI-XIX), Ayuntamiento de Huelva, Huelva, 1997, pp.173-202.

NÚNEZ ROLDÁN, F.: La vida rural en un lugar del señorio de Niebla: La Puebla de Guzmán (siglos XVI al XVIII). Huelva, Diputación Provincial, 1985.

--En los confines del Reino. Huelva y su Tierra en el siglo XVIII. Universidad de Sevilla. Sevilla, 1987.

OJEDA RIVERA, J. F.: Organización del territorio en Doñana y su entorno próximo (Almonte). Siglos XVIII-XX. Madrid, M A P A, I C O N A, 1987.

OLIVERA POLL, A. y ABELLÁN GARCÍA, A.: "Las nuevas poblaciones del siglo XVIII en España. Hispania, 46/163 (1986), Madrid, pp. 299-325.

ORTEGA LÓPEZ, M.: El problema de la tierra en el expediente de Ley Agraria. Madrid, Fundación Juan March, 1978.

--“Conflictividad social y reforma agraria en la España de Carlos III”, en Estructuras agrarias y reformismo ilustrado en la España del siglo XVIII. Actas del Seminario de Segovia sobre Agricultura e Ilustración en España. Madrid, Ministerio de Agricultura, 1989, pp. 663-684.

PENAA GUERRERO, M. A.: El tiempo de los franceses. La Guerra de la Independencia en el suroeste español. Huelva, Ayuntamiento de Almonte, 2000. 
PERDICES DE BLAS, L.: Pablo de Olavide: (1725-1803): el ilustrado. Editorial Complutense, Madrid, 1993.

--Ensayo sobre la bibliografía de las obras impresas y manuscritos de Pablo de Olavide. Jaén, Cámara Oficial de Comercio e Industria de la Provincia, 1994 (2 vols.).

-- "Agronomía y fisiocracia en la obra de Pablo de Olavide", en Economía y economistas españoles. Enrique Fuentes Quintana (Ed.), vol. 3, La Ilustración, Barcelona, 2000, pp. 275-302.

PERDICES DE BLAS, L. y REEDER, J.: El mercantilismo, politica económica y Estado nacional. Madrid, 1998.

PLA ALBEROLA, P.: "La jurisdicción alfonsina como aliciente para recolonización del territorio". Revista de Historia Moderna, no 12, 1993, pp. 109-121.

RAMÍREZ, B. A.: Diccionario de Bibliografía Agronómica de toda clase de escritos relacionados con la agricultura. Madrid, MAPA, 1988. (Primera edición por M. Rivadeneyra, Madrid, 1865).

Regla directiba, y constituciones de los empleos que tendràn los fieles que se uniesen en fraternal amor á la Hermandad de Nuestra Madre, y Señora del Rocio, Patrona, y Avogada de esta villa de Almonte, cuya Sagrada Milagrosa Imagen se venera en su santa Casa y Sagrado Templo, sita en el termino de esta villa. Sin pie de imprenta, [Sevilla?], 1758. Edición facsímil. Huelva, Ayuntamiento de Almonte, 2003.

ROBLEDO HERNÁNDEZ, R.: Economistas y reformadores españoles: la cuestión agraria (1760-1935). Madrid, MAPA, 1993.

RODRÍGUEZ-MONIINO SORIANO, R.: "Las nuevas poblaciones (y repoblación de sitios y lugares) durante el siglo XVIII e inicios del XIX en los fondos documentales del Archivo Histórico Nacional”. Boletín de la Real Academia de Córdoba de Ciencias, Bellas Letras y Nobles Artes, no 135, 1998, pp. 269-286.

ROMERO Y MORUBE, J.: Francisco de Bruna y Ahumada. Sevilla, Colegio Oficial de Aparejadores y Arquitectos Técnicos, 1997. (Obra facsímil de la editada en Sevilla en 1965).

RUÍZ GONZÁLEZ, J. E.: Estudio de la repoblación y colonización de Sierra Morena. Jaén, Cámara Oficial de Comercio e Industria, 1986. Tesis doctoral, ejemplar policopiado.

SÁNCHEZ SAUS, R.: Linajes sevillanos medievales. Sevilla, 1991

SARRAILH, J.: La España ilustrada de la segunda mitad del siglo XVIII. Fondo de Cultura Económica, México, Madrid, 1985.

SUÁREZ GALlEGO, J. M.: Fuero de las Nuevas Poblaciones de Sierra Morena y Andalucía y Legislación complementaria. Jaén, Ayuntamiento de Guarromán, 1992.

VELÁZQUEZ GAZTELU, J. P.: Catálogo de todas las personas ilustres y notables de esta ciudad de Sanlúcar de Barrameda. A. S. E. H. A., Cádiz, 1997.

WARD, BERNARDO: Proyecto económico Bernardo Ward. Edición y estudio preliminar de Juan Luis Castellano Castellano. Madrid, Instituto de Estudios Fiscales, 1982. 
